\title{
A MOdEL-BASEd DECISION SUPPORT TOOL FOR BUILDING PORTFOLIOS UNDER UNCERTAINTY
}

\author{
ABSTRACT \\ Despite abundant energy use data, few facilities managers have a good benchmark for tracking energy \\ performance in commercial buildings. Building energy self-benchmarking is an effective means of \\ comparing performance to expectations. This paper presents an improved theory for a decision support \\ tool that can self-benchmark building energy performance, identify energy faults, and quantify their \\ severity. Detailed building energy simulation modeling of a big-box retail store with open source \\ software is accessible and economical to industry for generating performance benchmarks. Methods of \\ parametric sampling and uncertainty analysis are enhanced with detailed parameter uncertainty \\ characterization. Uncertainty and sensitivity analysis are used to adjust risk tolerance thresholds for \\ each unique monitored end-use. A dynamic cost function allows utility theory to compute expected \\ costs covering multiple criteria. Improved theory for decision support tool is tested on ten faulted \\ model scenarios placed in three climate zones. Finally, we demonstrate fault response prioritization.
}

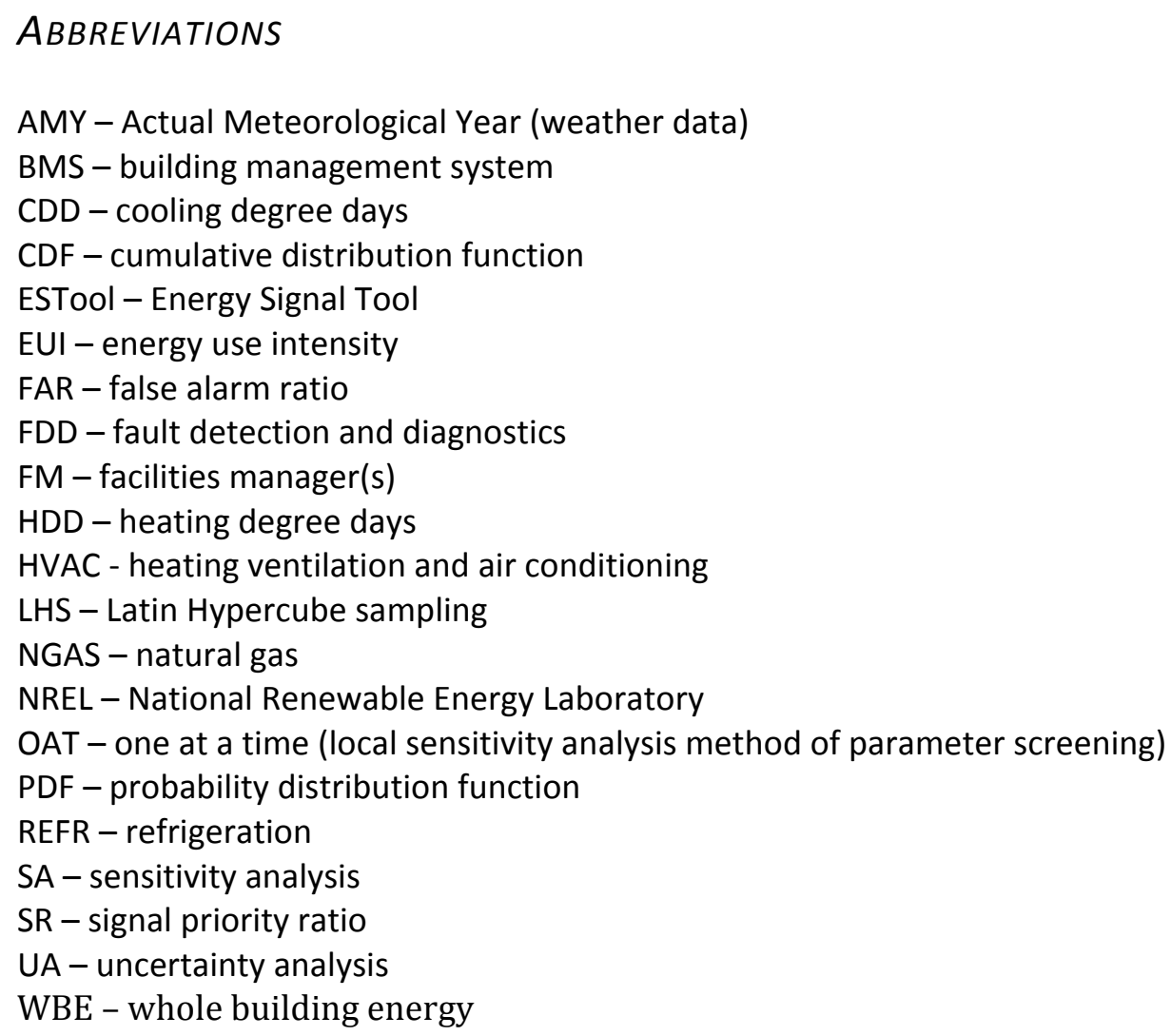

Page 1 of 30 
Email: eric.boxer@colorado.edu

\section{Introduction}

Standards such as LEED ${ }^{\circledR}$ guide energy efficient design, but the energy savings predicted by the design models often deviate significantly from actual building usage data [1]. The root causes of this gap include: (1) inaccurate assumptions in the design energy model relating to design, occupant behavior, or control strategies, (2) improper execution of intended construction, (3) unintended control strategies in the operation of building systems, and (4) poor assumptions in design [2]. Building energy performance benchmarking can reveal the presence of "faulted" operational states, as well as quantify the severity of these faults. There are two primary classes of building performance benchmarking: peer comparison of performance among other similar buildings, and self-benchmarking compared to an ideal baseline. This paper is focused on a tool for performing building self-benchmarking; one which requires a relatively high level of expertise to utilize.

Installing sub-metering infrastructure that monitors and records building energy end-uses can provide rich data for building energy self-benchmarking and is a prevailing trend for commercial buildings [3]. There is growing potential to utilize sub-metered data from categorical building systems' end-uses as a feedback mechanism that can help bridge the gap between intended and actual operation [4]. There are vast amounts of building energy data available to facilities managers (FM), however FM lack the resources to analyze it. Thus, the FM typically does not know if their buildings perform as they were intended.

Henze et al. [5] developed the concept of an Energy Signal Tool for operational performance decision support, which is made more credible and accurate with UA and probabilistic model predictions. The tool alerts facilities managers of building consumption anomalies across a variety of monitored end-use categories. Henze et al. [5] used utility theory to merge measured consumption data, probabilistic predictions, and a scalar cost function to provide easily interpreted visual results in the form of a fivelevel traffic light. In their work, user-defined risk tolerance thresholds give the user decision support for addressing and prioritizing energy-related faults in reference to measurements taken over a rolling retrospective period. The authors based their investigation on reduced order models developed in the Matlab technical computing environment for ease of data processing and maximum theoretical development.

This paper builds upon the concepts for an Energy Signal Tool (ESTool) as proposed by Henze et al. [5] with a more detailed modeling platform and alterations to the foundational theory. Here we use opensource detailed building energy simulation software common to engineering practitioners to create probabilistic predictions of performance. This paper also explores the use of UA and sensitivity analysis $(\mathrm{SA})$ in the context of setting risk tolerance thresholds, for which there is little previous research. We also show that risk-tolerance thresholds can be defined in a more sophisticated manner than arbitrary levels, involving a combination of probabilistic state masses and straightforward user input. The application of utility theory is enhanced by a novel approach of accepting input to the cost function from an ordinary user with several organizational objectives in mind. 


\section{Review of energy performance benchmarking practices}

The US EPA offers information on building performance assessment and benchmarking through its Energy Star Portfolio Manager program [6]. This system has participation from $40 \%$ of the US commercial building stock, which belies the simplicity of its use [6]. Individual building performance is compared to a peer group from the most recent CBECS data set, yielding a score that is a product of " $a$ statistical regression model that correlates the energy data to the property use details" [6, 7]. This rating system is the most rigorous peer benchmarking system of its kind in the United States [8]. Portfolio manager is an excellent starting point, and can help cities track goals toward progress such as Architecture 2030, but falls short of offering a benchmark that supports energy management activities. For example, Hinge et al. [9] found that Portfolio Manager scores for primary education facilities in the Northeast depended heavily on the amenities of the building (e.g., ventilation levels, technology), and the experience level of the facilities management personnel. Peer groups are static; an upgrade to the functions that a building provides will result in a reduced Portfolio Manager score [9]. Peer benchmarking in general also does not show efficiency gains when improvements in one end-use have been offset by changing operations that affect another.

A customized portfolio benchmarking method for restaurants was explored by Hedrick et al. [10]. The authors demonstrated that a benchmarking system tailored to each restaurant is the best way to evaluate performance. They took a statistical approach to benchmarking by deriving regression models for expected performance from best correlation of independent variables such as hours of operation, facility type, and observations in weather. This type of benchmark reveals whether or not one particular store is an outlier in the data set on a qualitative basis. It has the advantage of simplicity to the user, but may not be accurate independent variables that are hard to measure, such as local HDD and CDD, are missing or inaccurate.

With the increasing amount of sub-metered energy data available, it is a trend in industry to have more interest in advanced energy self-benchmarking. This has created the opportunity for a number of software as a service (SaaS) platforms being offered by companies such as Building IQ and Ecova-Verisae that are in high industry demand. These SaaS platforms offer features such as machine learning algorithms that use BMS data to filter out faulted conditions from normal anomalies to develop unique fit mathematical models capable of predictive optimization [11]. They also offer proactive optimization analysis in real time with expert staff available to guide customers to energy savings priorities [12]. This is excellent for managing opportunities in a building portfolio, but SaaS platforms are driven by reduced order models that use a select few observed environmental variables to predict normal energy consumption patterns. Mathematical algorithms cannot handle simple inputs such as operational schedules and HVAC controls logic that a detailed energy model can. This type of benchmarking solution does not offer combined decision support with energy benchmarks as well as other organizational priorities as inputs. Incorporating other goals, such as human comfort and sales, into the picture will be 
Corresponding author: Eric Boxer

Email: eric.boxer@colorado.edu

especially as businesses increase energy efficiency and thus decrease the cost share that energy has on their overall plan.

\section{Literature review}

Uncertainty analysis (UA) quantifies the uncertainty in model outcome due to the uncertainty that exists in the set of model input parameters [13]. Detailed energy simulation models have thousands of input parameters characterizing the usage patterns, operational strategy, and physical properties of a building and its systems. Even for existing buildings with extensive construction and operational documentation, there are uncertainties in some parameters such as outdoor air infiltration rate, occupancy schedules, and equipment performance curves. When using a detailed energy simulation model as a performance benchmark, it is a sure thing that a point estimate of energy use during any given period produced by the model will differ from the measured value. Various combinations of parameter values in the model will result in a range of model outcomes. UA is an important component of simulation models used for decision-making, as it acknowledges the unknowns that go into establishing a baseline [14]. Hopfe and Hensen [15] have demonstrated robust methods in which UA can be used in conjunction with sensitivity analysis to improve the decision making process in building design.

Booth and Choudhary [16] propose a framework of UA for assessing the potential impact of energy efficiency policy in UK housing. Their goal was to minimize the financial risk of program implementation to the UK government by providing a range of expected outcomes that result from retrofit measures that allows for spending prioritization. Wang et al. [17] used Monte Carlo analysis (MCA) to examine the uncertainties in building performance due to model accuracy, modeling assumptions, climatic data, and actual operational practices. These authors found a spread of up to $100 \%$ in energy consumption between a building operating in the worst and best possible manner, which is far greater than contributions most design features could make. Bucking et al. [18] used probability distributions of parameters extracted from solutions to a Net Zero Energy (NZE) building optimization algorithm to characterize uncertainty in energy performance. They generated probable ranges of energy performance by using random MCA sampling with batch sizes of 1000 models to sample from 26 uncertain model parameters. These authors were able to extract probability distribution functions of parameters that showed which values were most likely to result in a NZE-compliant design. Several other authors have worked with UA for building design optimization purposes [18, 19, 20, 21].

Calibration of a benchmark model is crucial for the success of self-benchmarking methods. Statistical calibration of a model is very challenging, as there are thousands of knobs to turn that could all potentially have an impact on helping the model match the measured data. This issue of overparameterization is compounded by limitations in computational power. Saltelli et al. [22] show how model parameter space can be reduced with a combination of local pre-screening and global sensitivity analysis. There are many examples of studies in the literature where the dozens of parameters that are contained in building simulation models are reduced to fewer than ten that have high significance to the model outcome $[15,18,21]$. 
In Heo et al. [23] a scalable, probabilistic methodology is presented that is based on Bayesian calibration of normative energy models. Based on CEN-ISO building standards, normative energy models are lightweight, quasi-steady state formulations of heat balance equations, which makes them appropriate for modeling large sets of buildings efficiently. Calibration of these models enables improved representation of the actual buildings and can include additional uncertainties associated with retrofit technologies to generate probabilistic predictions of energy savings. These authors reduce the number of calibration parameters by using the Morris parameter screening technique described by Saltelli et al.[16] in order to rank parameters by their relative effect on the energy consumption of the building. The authors follow the mathematical formulation of Bayesian calibration developed by Kennedy and O'Hagan [24] that captures three types of uncertainties: (a) parameter uncertainty in the energy simulation model, (b) discrepancy between the model and the true behavior of the building, and (c) observation errors. Using Bayes' theorem, they update the prior parameter distributions, and obtain posterior distributions of the model parameters given the observations similar to the process proposed by Henze et al [5].

It is typical for facilities and energy managers to be overloaded with alarms and notifications from the BMS or other FDD software for a portfolio of ever-more complex buildings. At the same time, submetered energy use data is underutilized. There is a need for a method to prioritize which buildings are most vital to address due to their states of energy consumption that could impact both energy costs and other organizational objectives. A tool that utilizes calibrated detailed building energy models run with actual weather data to generate probabilistic energy consumption predictions for segmented end-use categories would be of great value. This is now possible to accomplish using batch sample modeling methods to incorporate UA into such a tool - thus reducing the prediction/performance gap - with recent advancements to cloud-computing accessibility. All of this, as well as the need to translate massive amounts of data into output for prioritizing energy efficiency maintenance and retrofits, is addressed by this paper.

\section{Methodology of UA, SA, and baseline model}

The methodology employed in this work to generate the working basis of the ESTool included detailed building energy modeling, uncertainty analysis, sensitivity analysis, statistical calibration, and Monte Carlo sampling. Figure 1 below summarizes the overall process of preparing the energy model for use as a benchmarking tool.

$<$ Figure $1 ; 1.5$ columns>

\subsection{Methods of uncertainty analysis with OpenStudio}

Monte Carlo analysis performed with batch modeling is one method of exploring uncertainty propagation in model outcomes $[25,26,27]$ and thus generating probabilistic predictions. For this paper, the authors performed batch-modeling with cloud computing by utilizing the application program interface (API) provided by the OpenStudio 'Analysis Spreadsheet' - currently under development at 
Email: eric.boxer@colorado.edu

NREL [28]. The Analysis Spreadsheet communicates with the OpenStudio Server package to set up large batches of model runs [29]. These batches are executed on the Amazon Web Services (AWS) cloud computing platform. In this study, a typical batch of 1,000 annual model runs ran with a duration of about three hours.

\subsection{Parameter uncertainty characterization}

Model parameter uncertainty is characterized with probability distribution functions (PDFs), which may be either discrete or continuous in nature. Sampling across these uncertainties is what ultimately determines the degree of expected variability in energy consumption, and thus impacts the sensitivity of the Energy Signal Tool. Burhenne [26] describes four general sources of information to characterize parameter uncertainty distributions:

1. Physical bounds (whereby a uniform distribution is assumed lacking further information)

2. Literature references

3. Expert knowledge

4. Measurements

MacDonald, Corrado, Dominguez, and Stein all provide information on which to base assumptions regarding the distribution of parameter uncertainty [30, 31, 32, 33]. Up to this point, the vast majority of previous research involving UA has been for applications to design efforts and has not incorporated many of the parameters needed to simulate uncertainties in operation. Many assumptions of UA characterization are still at the discretion of the user due to lack of measured data [2]. Struck and Hensen [19] provide examples of making assumptions for uncertainty in un-measurable physical parameters.

For the Energy Signal Tool application, the range of uncertainty distributions should be based on the building operator's knowledge of the maximum and minimum values that could occur within normal operation but not including states of faulted operation. For example, it may be within reason that the coefficient of performance (COP) of a direct expansion (DX) cooling coil in an existing building could be $15 \%$ lower than rated, but below this level there would be some action recommended to fix it. This approach is taken so that a truly faulted operational state of some parameter would likely propagate to energy consumption that falls outside of the expected probabilistic consumption range.

For the case study building, many building parameters were deduced with high confidence during the initial building audit, or subsequently from sub-metered data, and through conversations with facility engineers. Other parameters were not possible to deduce with complete certainty from any available knowledge of the building or its physical properties.

Table 1, in section 4.4, lists initial parameter values and the probable ranges assumed for this case study. Sources referenced to characterize each parameter uncertainty distribution are listed in the fifth column and in greater detail in the footnote below. 
Email: eric.boxer@colorado.edu

\subsection{Parameter screening and model simplification}

\subsubsection{Local sensitivity analysis}

The number of model runs required to thouroughly explore the range of outcomes generated by parameter uncertainty can be decreased by model simplification. This is accomplished by reducing the number of parameters in the model that contain uncertainty dimensionality [13]. Initially, 37 model parameters were modeled as uncertain for the case study building. The one-at-a-time (OAT) parameter prescreening method was used to separate the influential from non-influential model parameters [13]. This limits the amount of effort required to characterize parameter uncertainty disitributions in detail. It also reduces the computational power needed to perform a sufficient quantity of sample simulations needed later on to fully characterize uncertainty in end-use consumption distributions.

Four end-uses were selected to 'sub-meter' in the case-study model; Natural Gas, HVAC electricity, refrigeration electricity, and whole building energy. These are noted throughout this report as "NGAS", "HVAC", and "REFR", and "WBE", respectively. Table 1 below lists parameter characterizations in terms of the nominally assumed parameter value, and the minimum and maximum values used for uncertainty sampling. The table also gives results of the parameter pre-screening process in terms of the significance index (SI) for each of the four end-uses; where parameter significance is defined as the relative effect that a shift in a single parameter value has on the outcome of each end-use [34]. Finally, ranks of parameter significance are given for each fuel category end-use. Model simplification was done, nominally, by retaining uncertainty in those parameters within the top $50^{\text {th }}$ percentile of significance index value to whole building energy. 
Corresponding author: Eric Boxer

Email: eric.boxer@colorado.edu

Table 1: List of screened model parameters and results of OAT pre-screening

\begin{tabular}{|c|c|c|c|c|c|c|c|c|c|}
\hline Parameter description (units) & $\begin{array}{c}\mu / \text { Initial } \\
\text { value }\end{array}$ & $\min$ & $\max$ & $\begin{array}{l}\text { Char. } \\
\text { Source }_{1}\end{array}$ & SI NGAS & SI HVAC & SI REFR & SI WBE & $\begin{array}{l}\text { Rank } \\
\text { WBE }\end{array}$ \\
\hline Space infiltration & various & $-40 \%$ & $+40 \%$ & 1,2 & $60.4 \%$ & $52.3 \%$ & $0.2 \%$ & $17.5 \%$ & 1 \\
\hline Rated gas burner eff. & $80 \%$ & $60 \%$ & $81 \%$ & 6 & $28.6 \%$ & $24.2 \%$ & $0.0 \%$ & $8.9 \%$ & 2 \\
\hline Heating setpoint $\left({ }^{\circ} \mathrm{C}\right)$ & $15-20$ & -2 & 2 & 7 & $15.7 \%$ & $13.8 \%$ & $1.2 \%$ & $6.0 \%$ & 3 \\
\hline Space light power* & various & $-18.6 \%$ & $+18.6 \%$ & 8 & $13.2 \%$ & $10.0 \%$ & $0.2 \%$ & $5.7 \%$ & 4 \\
\hline Wall / roof conductivity & various & $-20 \%$ & $+20 \%$ & 3 & $13.5 \%$ & $12.0 \%$ & $0.5 \%$ & $4.9 \%$ & 5 \\
\hline Heating supply air temp $\left({ }^{\circ} \mathrm{C}\right)$ & 16.7 & 14.7 & 18.7 & 6 & $10.6 \%$ & $8.8 \%$ & $1.4 \%$ & $3.5 \%$ & 6 \\
\hline Space plug load power* & various & $-18.2 \%$ & $+18.2 \%$ & 8 & $6.0 \%$ & $4.2 \%$ & $0.2 \%$ & $2.9 \%$ & 7 \\
\hline Heating sizing factor & 1.2 & 1.1 & 1.4 & 6 & $7.0 \%$ & $6.6 \%$ & $0.4 \%$ & $2.5 \%$ & 8 \\
\hline HX sensible effectiveness & $76 \%$ & $60 \%$ & $76 \%$ & 6 & $6.4 \%$ & $5.5 \%$ & $0.2 \%$ & $2.1 \%$ & 9 \\
\hline Fan pressure rise & various & $-30 \%$ & $+30 \%$ & 6 & $4.0 \%$ & $2.9 \%$ & $0.1 \%$ & $1.9 \%$ & 10 \\
\hline Minimum outside airflow ratio & 0.3 & 0.3 & 0.5 & 7 & $4.8 \%$ & $4.0 \%$ & $0.2 \%$ & $1.5 \%$ & 11 \\
\hline Roof absorptance & 0.3 & 0.3 & 0.7 & 7 & $3.5 \%$ & $2.3 \%$ & $0.0 \%$ & $0.9 \%$ & 12 \\
\hline Min. refr. condensing temp $\left({ }^{\circ} \mathrm{C}\right)$ & $21-24$ & -3 & 3 & 6 & $0.0 \%$ & $0.0 \%$ & $4.0 \%$ & $0.7 \%$ & 13 \\
\hline Fan efficiency & $45 \%$ & $35 \%$ & $48 \%$ & 6 & $1.2 \%$ & $1.8 \%$ & $0.0 \%$ & $0.7 \%$ & 14 \\
\hline Cooling coil COP & 4 & 3 & 4.1 & 6 & $0.0 \%$ & $1.6 \%$ & $0.0 \%$ & $0.6 \%$ & 15 \\
\hline Refrigeration suction piping UA & various & $-25 \%$ & $25 \%$ & 6 & $0.2 \%$ & $0.3 \%$ & $11.2 \%$ & $0.6 \%$ & 16 \\
\hline Anti-sweat energy & various & $-50 \%$ & $+0 \%$ & 6 & $0.6 \%$ & $0.6 \%$ & $0.5 \%$ & $0.3 \%$ & 17 \\
\hline Max heat/cool point - tstat float $\left({ }^{\circ} \mathrm{C}\right)$ & 0.278 & 0.2 & 0.8 & 6 & $0.1 \%$ & $0.8 \%$ & $0.5 \%$ & $0.3 \%$ & 18 \\
\hline Walk-in cooler temp $\left({ }^{\circ} \mathrm{C}\right)$ & 0 & -3 & 1 & 6 & $0.1 \%$ & $0.2 \%$ & $0.9 \%$ & $0.2 \%$ & 19 \\
\hline Space cooling setpoint $\left({ }^{\circ} \mathrm{C}\right)$ & $23-27$ & -2 & 2 & 7 & $0.3 \%$ & $0.7 \%$ & $0.0 \%$ & $0.2 \%$ & 20 \\
\hline Space thermal mass & various & $-30 \%$ & $+30 \%$ & 6 & $0.8 \%$ & $0.5 \%$ & $0.1 \%$ & $0.2 \%$ & 21 \\
\hline HVAC system cycling run time (sec) & 1800 & 1200 & 2400 & 7 & $0.5 \%$ & $0.4 \%$ & $0.0 \%$ & $0.2 \%$ & 22 \\
\hline Wall specific heat & various & $-29 \%$ & $+29 \%$ & 4 & $0.4 \%$ & $0.3 \%$ & $0.1 \%$ & $0.1 \%$ & 23 \\
\hline Operating ref case temp $\left({ }^{\circ} \mathrm{C}\right)$ & various & -2 & 3 & 6 & $0.2 \%$ & $0.1 \%$ & $0.3 \%$ & $0.1 \%$ & 24 \\
\hline Cooling sizing factor & 1.2 & 1.1 & 1.4 & 6 & $0.2 \%$ & $0.5 \%$ & $0.4 \%$ & $0.1 \%$ & 25 \\
\hline Supply fan medium flow (flow ratio) & 0.8 & 0.7 & 0.9 & 6 & $0.1 \%$ & $0.2 \%$ & $0.0 \%$ & $0.1 \%$ & 26 \\
\hline Suply fan minimum flow (flow ratio) & 0.4 & 0.3 & 0.6 & 6 & $0.0 \%$ & $0.0 \%$ & $0.0 \%$ & $0.1 \%$ & 27 \\
\hline Economizer $\mathrm{OA}$ temp high limit $\left({ }^{\circ} \mathrm{C}\right)$ & 18.3 & 16.3 & 20.3 & 7 & $0.0 \%$ & $0.0 \%$ & $0.1 \%$ & $0.0 \%$ & 28 \\
\hline Building occupancy (total people) & 160 & 48 & 480 & 7 & $0.1 \%$ & $0.1 \%$ & $0.2 \%$ & $0.0 \%$ & 29 \\
\hline Economizer OA temp low limit $\left({ }^{\circ} \mathrm{C}\right)$ & 10 & 8 & 12 & 6 & $0.1 \%$ & $0.1 \%$ & $0.2 \%$ & $0.0 \%$ & 30 \\
\hline Cooling supply air temp $\left({ }^{\circ} \mathrm{C}\right)$ & 12.8 & 10.8 & 14.8 & 6 & $0.0 \%$ & $0.0 \%$ & $0.0 \%$ & $0.0 \%$ & 31 \\
\hline Ref: ratio evap rate to latent capacity & 1.5 & 1 & 2 & 6 & $0.0 \%$ & $0.0 \%$ & $0.0 \%$ & $0.0 \%$ & 32 \\
\hline Fan motor efficiency & $90 \%$ & $75 \%$ & $93 \%$ & 6 & $0.0 \%$ & $0.0 \%$ & $0.0 \%$ & $0.0 \%$ & 33 \\
\hline Zone air mixing flow rate $(\mathrm{m} 3 / \mathrm{s})$ & 2 & 0.5 & 3.5 & 6 & $0.0 \%$ & $0.0 \%$ & $0.0 \%$ & $0.0 \%$ & 34 \\
\hline Fraction of anti-sweat to case load & 0.85 & 0.7 & 1 & 7 & $0.0 \%$ & $0.0 \%$ & $0.0 \%$ & $0.0 \%$ & 35 \\
\hline Refr. ondenser fans min flow & $20 \%$ & $20 \%$ & $50 \%$ & 6 & $0.0 \%$ & $0.0 \%$ & $0.0 \%$ & $0.0 \%$ & 36 \\
\hline
\end{tabular}

\subsubsection{Limitations to model simplification}

Model simplification for the Energy Signal Tool has special considerations and limitations. Chiefly, model simplification is limited by how it affects the magnitude of uncertainty that is propagated into the expected consumption distribution of each end-use being monitored. Removing parametric uncertainty that significantly affects the distribution of expected energy consumption for any given end-use in a

${ }^{1}$ Key of sources used to characterize parameter uncertainty distributions given in Table 1: 1. ASHRAE [35]; 2 . Stein [33]; 3. Dominguez [32]; 4. MacDonald [30]; 5. Corrado [31]; 6. Expert judgment of authors; 7. Conversations with industry partner FM; 8. Sub-metering data at case study building 
Email: eric.boxer@colorado.edu

given span of time is treacherous; it would compromise the ESTool's ability to predict the acceptable range of consumption. Therefore, the model simplifcation process should be validated in each case.

\subsubsection{Validation of model simplification}

We validate model simplification by comparing the distributions of a set of results from the model with larger parameter space with the set of results from the model with the new, simplified, parameter space. Reddy recommends a batch size of $n(k+2)$ runs to compare simulation output; where $k$ is the number of uncertain parameters in the model, and $n$ is the quantity of discrete values of these variables [25]. Since uncertain parameters were modeled with continuous distribution, $n$ was set to 10 for these purposes. Therefore, 390 and 200 random sample runs were performed for the models with 37 and 18 dimensions of uncerrtain parameter space, respectively. Figure 2, below, gives a comparison of all enduse distributions for both the 18 and 37 parameter models.

<Figure 2; 1.5 columns >

A test for significant difference in the mean values of can be used to compare two independent populations shown in Figure 2 above [36]. For the two models with uncertain parameter counts of 37 and 18 , we present a test for the difference in mean values of population 1 and 2 , respectively, as follows:

Null Hypothesis $\left(H_{0}\right): \mu 1-\mu 2=0$

Alternate Hypothesis: $\mathrm{H} 1: \mu 1-\mu 2 \neq 0$

Confidence Level: $99 \%(\alpha=0.01)$

Test Statistic: $z_{O}=\frac{\bar{x}_{1}-\bar{x}_{2}-0}{\sqrt{\frac{s_{1}^{2}}{n_{1}}+\frac{s_{2}^{2}}{n_{2}}}}$

Where,

$$
\begin{aligned}
& \mathrm{n} 1=380 \\
& \mathrm{n} 2=190
\end{aligned}
$$

Rejection Criteria: Reject $\mathrm{H}_{0}$ if $\mathrm{z}_{0}>2.326\left(\mathrm{z}_{0.01}\right)$

Table 2, below, gives results of these computations for the case study. 
Corresponding author: Eric Boxer

Email: eric.boxer@colorado.edu

Table 2: Results of test for significant difference in means of two populations

\begin{tabular}{ccccccccc}
\hline & $\bar{x}_{1}$ & $\bar{x}_{2}$ & $S_{1}^{2}$ & $S_{2}^{2}$ & $n 1$ & $n \mathbf{n}$ & $Z_{0}$ & $P$-value \\
\hline WBE & 776.615 & 780.93 & 1019.13 & 1200.885 & 380 & 190 & 1.438144 & 0.075 \\
NGAS & 299.496 & 300.237 & 939.949 & 1044.456 & 380 & 190 & 0.262464 & 0.397 \\
HVAC & 58.787 & 59.068 & 35.467 & 39.373 & 380 & 190 & 0.512555 & 0.304 \\
REFR & 127.511 & 127.6411 & 5.149 & 5.35 & 380 & 190 & 0.637042 & 0.262 \\
\hline
\end{tabular}

The test gave strong evidence to accept $\mathrm{H}_{0}$ for all four end-uses. Therefore, the model reduction was considered valid. In the case where significant differences are found, the pre-screening process would be iterative until an acceptable solution is obtained.

\subsection{Global sensitivity analysis}

From a global perspective, a parameter is influential if its effect on the model objective outcome is proportionally larger than that of others across a wide range of global model conditions [18]. For this consideration of multi-dimensional uncertainty, global SA is superior to local SA. Saltelli et al. [22] describe methods of global SA for complex models. Global SA has dual purpose for setting up the ESTool : (1) to reduce model dimensionality by relative significance, and (2) to quantify the impact that each parameter has on each modeled end-use with an absolute measure.

The following table gives global sensitivity analysis results for all end-uses of the case study building as modeled in all three climate zones (the significance of modeling in three climate zones is explained in section 9). The values in Table 3 represent the relative significance of each parameter to each end-use sorted by a column for each climate zone. 
Email: eric.boxer@colorado.edu

Table 3: Global sensitivity analysis results for four end-uses by ASHRAE climate zone ${ }^{2}$

\begin{tabular}{|c|c|c|c|c|c|c|c|c|c|c|c|c|}
\hline Parameter & \multicolumn{3}{|c|}{ WBE } & \multicolumn{3}{|c|}{ NGAS } & \multicolumn{3}{|c|}{ HVAC } & \multicolumn{3}{|c|}{ REFR } \\
\hline Climate zone> & $6 a$ & $4 \mathrm{c}$ & $3 a$ & $6 a$ & $4 c$ & $3 a$ & $6 a$ & $4 c$ & $3 a$ & $6 a$ & $4 c$ & $3 a$ \\
\hline Space infiltration & 1.000 & 1.000 & 1.000 & 1.000 & 1.000 & 1.000 & 0.376 & 0.393 & 0.662 & 0.027 & 0.116 & 0.042 \\
\hline Gas burner eff. & 0.652 & 0.315 & 0.223 & 0.711 & 0.375 & 0.319 & - & - & - & - & - & - \\
\hline Heating setpoint $\left({ }^{\circ} \mathrm{C}\right)$ & 0.408 & 0.170 & 0.525 & 0.353 & 0.195 & 0.509 & 0.021 & 0.002 & 0.277 & 0.269 & 0.033 & 0.033 \\
\hline Wall / roof conductivity & 0.302 & 0.385 & 0.410 & 0.282 & 0.410 & 0.399 & 0.079 & 0.062 & 0.246 & 0.033 & 0.004 & 0.025 \\
\hline Heating supply air temp $\left({ }^{\circ} \mathrm{C}\right)$ & 0.087 & 0.150 & 0.121 & 0.052 & 0.179 & 0.171 & 0.001 & 0.000 & 0.003 & 0.153 & - & - \\
\hline Heating sizing factor & 0.095 & 0.040 & 0.290 & 0.076 & 0.001 & 0.114 & 0.223 & 0.202 & 0.446 & 0.002 & 0.021 & 0.102 \\
\hline HX sensible effectiveness & 0.157 & 0.646 & 0.513 & 0.169 & 0.704 & 0.646 & 0.001 & 0.000 & 0.000 & 0.003 & 0.001 & 0.001 \\
\hline Fan pressure rise & 0.056 & 0.194 & 0.442 & 0.027 & 0.329 & 0.288 & 1.000 & 1.000 & 1.000 & 0.015 & - & - \\
\hline Minimum outside airflow ratio & 0.062 & 0.006 & 0.001 & 0.061 & 0.006 & 0.003 & 0.006 & 0.002 & 0.000 & 0.008 & - & - \\
\hline Roof absorptance & 0.037 & 0.178 & 0.068 & 0.053 & 0.236 & 0.221 & 0.094 & 0.003 & 0.106 & - & - & - \\
\hline Refrigeration suction piping UA & 0.007 & 0.259 & 0.344 & 0.002 & 0.001 & 0.000 & 0.036 & 0.082 & 0.082 & 1.000 & 1.000 & 1.000 \\
\hline Min. refr. condensing temp $\left({ }^{\circ} \mathrm{C}\right)$ & 0.003 & 0.002 & 0.135 & - & - & - & 0.001 & 0.000 & 0.000 & 0.467 & 0.087 & 0.774 \\
\hline Fan efficiency & 0.005 & 0.043 & 0.129 & 0.006 & 0.096 & 0.080 & 0.555 & 0.552 & 0.545 & 0.001 & 0.000 & 0.000 \\
\hline Cooling coil COP & 0.011 & 0.019 & 0.096 & - & - & - & 0.375 & 0.089 & 0.278 & 0.000 & - & 0.000 \\
\hline Anti-sweat energy multiplier & 0.000 & - & - & - & - & - & 0.000 & 0.000 & 0.000 & 0.000 & - & 0.000 \\
\hline Anti-sweat energy multiplier & 0.034 & 0.117 & 0.208 & 0.004 & 0.076 & 0.118 & 0.243 & 0.180 & 0.270 & 0.057 & 0.067 & 0.062 \\
\hline Walk-in cooler temp $\left({ }^{\circ} \mathrm{C}\right)$ & 0.002 & 0.007 & 0.011 & - & - & - & 0.022 & 0.009 & 0.010 & 0.139 & 0.056 & 0.079 \\
\hline Space cooling setpoint $\left({ }^{\circ} \mathrm{C}\right)$ & 0.010 & - & 0.074 & 0.000 & 0.000 & 0.001 & 0.053 & 0.015 & 0.234 & 0.000 & 0.000 & 0.011 \\
\hline
\end{tabular}

The parameter of primary significance to each end-use was not found to differ among climate zones for this particular building. The impacts of lower ranked parameters on model outcome were found to vary significantly across climate zones. For example, the efficiency of the gas burner was much more significant in the cold climate zone 6a. This is important information for setting the risk-tolerance thresholds. We explain this and other reasoning for setting up testing across three climate zones in section 9.

\subsection{Model calibration criteria}

End-uses monitored by the ESTool are likely to be components of fuel categories, and the purpose of the tool is to assess performance in each end-use. Moreover, the levels of calibration accuracy suggested by ASHRAE Guideline 14 (+/- 5\% NMBE and +/- 15+ CVRMSE) are insufficient to reduce model uncertainty to levels that support decision making relating to moderate abnormalities in energy consumption [37]. The detailed benchmark model should be calibrated to a level of error that is less than the minimum risk tolerance threshold for the ESTool; typically in the range of 3-5\% on a monthly basis. For this work, Latin Hypercube Monte Carlo sampling was used to generate 8,000 models with sample combinations of 18 uncertain parameters. LHS is generally a more efficient sampling method than pure random sampling when the total number of samples is restricted when using detailed energy modeling to obtain output. Cluster analysis was then used to select the most probable model from the set of calibrated solutions [8, 25]

\footnotetext{
${ }^{2}$ Values with "_" in Table 3 indicate that the end use did not require a customized cost function for the ESTool to be applied in that climate zone.
} 


\section{Risk tolerance in energy management}

Facilities managers often make choices about how to operate their buildings that affect energy use. However, rather than waiting for utility bill analysis or feedback from building occupants, they need a more transparent view of how their actions affect energy use and building performance. Vast amounts of complex metered data can provide this service, but automated data simplification is required to achieve true transparency. The decision analysis component of the Energy Signal Tool transforms metered data and complex model output into a simplified visual output that also accounts for costs of different courses of action. Comparing monitored data to a reasonable range of expectations will help the FM determine when corrective action (such as repair or retro-commissioning) is likely to be cost effective. This output cannot replace the judgment of the FM, but will greatly aid in a complex multiple criteria decision-making process.

\section{Proposed utility theory for the ESTool}

When uncertainty in building energy performance is acknowledged, energy management can be viewed in terms of risk management motivated by the probability and cost of a fault condition. Utility theory can be used in the context of building energy assessment by combining a model-based quantification of the conditional distribution of energy consumption with the cost of a range of actions for a range of associated states to obtain expected cost. Specifically, utility theory is used in the Energy Signal Tool to recommend the action that minimizes expected cost, given a specific measured observation in the context of expectations for that observation [5]. The two pieces of information needed to compute expected cost are show in Equation 1 below.

\section{Expected Cost $[E]=[$ Cost function $][$ State probabilities $]$}

In this paper, we significantly modify the original theory developed by Henze et al. [5], and seek to clarify its basis. Henze et al. [5] had defined thresholds of risk tolerance somewhat arbitrarily as a percentage deviation from the measured energy consumption. Here, we present the advantage of defining these thresholds by probability mass areas bounding the measured consumption. This makes use of informed parameter uncertainty distributions and enriches the decision tool with other readily available information in the process described below.

\subsection{Calculating state probabilities}

We propose that risk tolerance probability masses, $\mathrm{M}_{1}$ and $\mathrm{M}_{2}$, are calculated for each end use as a percentage of the total end-use uncertainty distribution mass after considering several variables described below. These red, yellow, and green probability masses outlined by the risk tolerance thresholds in Figure 3, below, comprise the state probabilities that go into the expected cost calculation. Thus, the state probabilities ultimately lead directly to the actionable information that this theory provides. The five probability masses, named $\left\{\mathrm{P}_{1}, \mathrm{P}_{2}, \mathrm{P}_{3}, \mathrm{P}_{4}, \mathrm{P}_{5}\right\}$, are bounded by a set of four energy consumption threshold values $\left\{\mathrm{M}_{\text {low }}, \mathrm{M}_{\text {high }}, \mathrm{M}_{\text {vlow }}, \mathrm{M}_{\text {vhigh }}\right\}$. . 
Email: eric.boxer@colorado.edu

<Figure 3, 1 column>

The green region defines the probability range within which the measured consumption is acceptably close to the expected value. This is bounded on the outer edges by the values of $M_{\text {low }}$ and $M_{\text {high }}$. The green region probability mass is highest when observed consumption falls at the most likely expected consumption. The yellow regions define the probability ranges where the measured data are slightly higher or slightly lower than model expectations. The outer bounds of this region are the values of $\mathrm{M}_{\text {vlow }}$ and $\mathrm{M}_{\text {vhigh. }}$. Finally, the red region defines the probability range where the measured data is much higher or much lower than model expectations. Both the consumption threshold values and the sizes of the probability masses will shift depending on where measured energy use falls within the context of the expected consumption distribution. For example, as measured consumption shifts higher than the expected distribution modal value, the probability mass of most likely normal consumption shrinks, while the mass of much higher than expected consumption increases. Determining these probability masses is the crux of the calculations in this section. Later on, it is explained how the marginal threshold values $\left\{M_{\text {low }}, M_{\text {high }}, M_{\text {vlow }}, M_{\text {vhigh }}\right\}$ are derived from the adjusted values of $M_{1}$ and $M_{2}$.

\subsection{Adjustment of risk tolerance thresholds for end-use controllability}

We suggest nominal values of $5 \%$ and $10 \%$, for probability masses $M_{1}$ and $M_{2}$ respectively, for the ESTool application. This places the first risk tolerance threshold comfortably outside of sub-metering measurement uncertainty. Thresholds $M_{1}$ and $M_{2}$ can be adjusted for the controllability and expected seasonal variation in consumption for each end use.

In this paper we define uncontrollable variables as those variables which facilities managers are not accountable for in their regular duties of maintaining optimal energy performance in a building. Where it is known that uncontrollable variables such as the customer volume or infiltration are likely to affect end-use consumption on a regular or cyclical basis, there can be greater risk acceptance for that enduse. This is incorporated by scaling up the risk tolerance thresholds $M_{1}$ and $M_{2}$. In other cases, for example where it is known that only easily controllable variables common to ongoing commissioning efforts (such as set points, scheduling, or combustion efficiency) are likely to affect end-use consumption on a regular basis, the user may want smaller values of $M_{1}$ and $M_{2}$ to reflect greater accountability for the outcome.

We propose here that the degree of controllability or uncontrollability for each end-use can be derived from a weighted classification of all parameters modeled with uncertainty. From the global sensitivity analysis, parameter significance index ( $\mathrm{SI}$ ) values are obtained, which quantify the relative influence that each uncertain parameter has on each end-use. Then, each parameter included in the global sensitivity analysis is classified as controllable ("c") or uncontrollable ("u"). Finally, Equations 2 and 3 illustrate how controllability (" $C$ ") and uncontrollability (" $U$ ") are computed for each end-use. 
Corresponding author: Eric Boxer

Email: eric.boxer@colorado.edu

$$
\begin{gathered}
\boldsymbol{C}=\frac{\sum_{\text {param }}^{\text {all=" } c^{\prime \prime}\left(S I_{\text {param }}\right)}}{\sum_{\text {param }}^{\text {all }}\left(S I_{\text {param }}\right)} \\
U=\frac{\sum_{\text {param }}^{\text {all }=" u^{\prime \prime}\left(S I_{\text {param }}\right)}}{\sum_{\text {param }}^{\text {all }}\left(S I_{\text {param }}\right)}
\end{gathered}
$$

The weighting of uncontrollable vs. controllable parameter significance is used calculate adjusted risk tolerance thresholds, $M_{1, c}$, and $M_{2, c}$ in Equations 4 and 5, whereby probability masses can be increased or decreased by up to $50 \%$. This specific enhancement over Henze et al., [5] allows a user to capture more faulted conditions for uses with greater controllability, and reduce the number of false alarms for end-uses with less controllability.

$$
\begin{aligned}
& M_{1, c}=M_{1}+0.05\left(\frac{\frac{U}{U+C}-0.5}{0.5}\right) \\
& M_{2, c}=M_{2}+0.10\left(\frac{\frac{U}{U+C}-0.5}{0.5}\right)
\end{aligned}
$$

\subsection{Adjustment of risk tolerance for seasonal variation}

It is proposed that risk tolerance thresholds can also be adjusted for known seasonal variations in the expected energy consumption magnitudes of each end-use. During weeks or months when end-use energy consumption costs of an end-use are much lower than during peak seasons for the specific enduse, this adjustment can help shield the user from unnecessary action signals and alarm fatigue.

A seasonal normalization multiplier for risk tolerance should be a multiplier that increases exponentially in non-critical seasons. A case in point is natural gas heating use; which in the summer months may be at $1 \%$ or less of its peak winter month value. Summer gas usage may only be for secondary purposes such as domestic hot water or cooking, and slight inaccuracies in the model could easily generate a false alarm for deviation from expected gas consumption. Thus, a multiplier $F_{n}$ would be applied to the probability masses for gas consumption in summer months. This multiplier should increase exponentially to account for the growing likelihood of low-magnitude model errors having an impact on results as the ratio of gas usage to maximum gas usage for a period of similar length decreases.

And, new adjusted risk tolerance threshold probability masses $M_{1, a}$ and $M_{2, a}$ are defined, finally, as follows in Equation 7:

$$
\begin{aligned}
& M_{1, a}=F_{n} M_{1, c} \\
& M_{2, a}=F_{n} M_{2, c}
\end{aligned}
$$

\subsection{Calculating the state boundaries}


Once $M_{1, a}$ and $M_{2, a}$ are obtained, the fundamental theorem of calculus (Equation 8 ) is used to determine the values of energy consumption ( $\mathrm{M}_{\text {vlow, }} \mathrm{M}_{\text {low }}, \mathrm{M}_{\text {high, }}$ and $\left.\mathrm{M}_{\text {vhigh }}\right)$, represented by the value $a$, that form the state probability boundaries for each end use.

$$
\int_{a}^{b} f(x) d x=F(b)-F(a)=A
$$

Where $F(x)$ denotes the inverse function, and $A$ represents some known area. Equations 9 and 10 can be used to solve for $a$ :

$$
\begin{gathered}
F(a)=F(b)-A \\
F^{-1}(F(a))=F^{-1}(F(b)-A)
\end{gathered}
$$

For the sake of brevity, we omit the intermediate details of this computation. In summary, the resultant values of $M_{\text {vlow, }} M_{\text {low, }}, M_{\text {high, }}$ and $M_{\text {vhigh }}$ are derived on the basis of the difference in the cumulative distribution function from the median $(\bar{e})$ of the expected consumption data for a given time period to an outer edge defined by $\bar{e}+M 1_{a}$ or $\bar{e}+M 2_{a}$. The resulting consumption differentials are applied to a measured consumption value $\left(X_{\text {meas }}\right)$ to obtain the risk tolerance levels in terms of energy consumption.

An illustration of calculating the risk tolerance threshold values is given in Figure 4 below. It is important to reiterate that the differentials added to the measured consumption value to obtain the risk tolerance thresholds are based on the difference from the expected median. In this way, state probability limits are less likely to exceed the boundaries of expected end-use distributions with skewness. Final resultant state probability masses are then recalculated based on the bounds calculated around $\mathrm{X}_{\text {meas. }}$.

$<$ Figure 4, 2 columns $>$.

Ultimately, some feedback from FM is needed to arrive at risk tolerance thresholds that meet the needs of the organization. This is on par with some of the engagement required by SaaS platforms [11, 12]. We suggest that this adjustment would be made to the initial values of $M_{1}$ and $M_{2}$ to avoid nullifying the intelligent adjustments described in sections 6.2 and 6.3 .

\subsection{The cost function}

There are essentially two dimensions when considering costs of facilities management; the costs of problems, and the costs of solutions to those problems. Therefore, the cost function is a two dimensional matrix with each entry showing the cost of a particular action in a particular state [5]. Values in the cost matrix are meant to be scalar, abstract, costs, not necessarily the actual cost of a service call or even proportionally accurate. In the absence of other information about cost considerations for the building end-use, the $5 \times 5$ neutral cost function, as shown below in Equation 16, us used. 


\subsection{The neutral cost matrix}

$$
\left|\begin{array}{lllll}
0 & 2 & 4 & 6 & 8 \\
2 & 0 & 2 & 4 & 6 \\
4 & 2 & 0 & 2 & 4 \\
6 & 4 & 2 & 0 & 2 \\
8 & 6 & 4 & 2 & 0
\end{array}\right|
$$

We will clarify here that the highest costs serve the purpose of preventing the costliest actions; e.g., responding the wrong way to much higher or lower energy. The lowest cost values encourage appropriate action, when applied to the expected cost function described below. By adding across each row of the cost matrix, the total possible cost (which is abstract) of each action is determined. Lacking contextual information about the scenario, the total cost of taking action (top row or bottom row of cost function) will always be higher than not taking action, since taking action means the facilities manager is initiating a service call. By adding down each column of the cost matrix, the relative cost of each state is determined. In this way, the leftmost and rightmost columns describe the most costly states, where consumption is much lower or higher, respectively, than expected. The range of values, as well as the symmetry or asymmetry, in the cost function are dependent upon the end-use application. Strategies for customizing the cost function are also described below.

\subsection{Expected cost function to generate signals}

In an application of utility theory, the expected cost vector $\left(E_{c}\right)$ is generated by taking the dot product of the cost function and the state probability vector as shown by Henze et al. [5]. The action signal corresponds to the minimum value of the resultant $E_{c}$.

The overall process of going from raw data to generating energy signals is illustrated in Figure 5 below.

$<$ Figure 5, 2 columns $>$

\section{Configuring the ESTool to support appropriate decisions and action prioritization}

In addition to energy efficiency, most organizations hold several aspects of building system operation important. The functions that end-uses provide are inevitably more valuable to an organization than the energy they consume to provide them. A typical building portfolio operator is faced with many building automation system warnings and alarms. By enriching the energy signal with priority information, they are empowered to determine specific end-use categories at certain buildings that will likely provide the 
Corresponding author: Eric Boxer

Email: eric.boxer@colorado.edu

most value for the time spent addressing them. Considering these issues, we show here that the cost function and the expected energy consumption distribution can be used to prioritize outcomes from the ESTool.

\subsection{Customizing the cost function to prioritize signals}

The cost function offers the opportunity to incorporate specific cost considerations for each end use into the energy signal tool. Portions of the cost matrix can be scaled differently for each end use with simple math. Bias can be introduced in the cost matrix to reflect specific cost considerations. For example, actions to address lower than expected energy use at a grocery store for a refrigeration system (caused by a broken evaporator fan, for example) would have a different priority level than actions to address low energy use for a cooling system in a cool climate because the cost of losing refrigerated inventory is much greater than the cost of space cooling malfunction. Therefore, questions such as the following two should be considered for each end-use when building the cost function.

1. Is the ratio of $\frac{\text { cost to maintain }}{\text { cost to operate }}$ high or low? (A: High, Low, N/A)

2. Does high or low energy consumption measurement, relative to expectations, indicate the possibility of serious problems that are damaging to broader organizational goals? (A: High, Low, $N / A)$

The first question considers a scenario where if maintenance costs are high relative to operational costs, bias should be introduced to discourage action and minimize the number of alarms generated. Regarding the second question, if the cost of energy is very high compared to the value of the goods or services of that end-use, then a cost function bias should encourage action and give this end-use high priority. If the response to both questions is neutral, then the cot function can remain unaltered.

\subsection{Prioritizing action based on expected energy cost deviation}

The primary benefit of incorporating uncertainty in decision support is the ability to quantify the urgency of responding to a situation [5]. Presenting a range (e.g., the $95 \%$ confidence interval) of cost deviation can be the most appealing performance metric for facilities managers. In the context of expected energy consumption distribution based on parameter uncertainty, this would be calculated as the difference between the observed energy cost over a given period and the high and low ends of the $95 \%$ confidence interval for the expected cost. The probable cost deviation ranges are calculated as shown in Figure 6, and as calculated in Equation 19 below.

<Figure 6, 1 column>

Equation 19 below describes how cost deviation is calculated. 
Corresponding author: Eric Boxer

Email: eric.boxer@colorado.edu

$$
C_{d, j}=(\text { unit cost })\left(\left(X_{m e a s}-X_{97.5}\right):\left(X_{\text {meas }}-X_{2.5}\right)\right)
$$

Where

$$
\begin{aligned}
& C_{d, j}=95 \% \text { confidence interval for the range of deviation of observed from expected cost } \\
& \text { unit cost }=\text { Unit cost of energy in } \$ / \mathrm{kWh} \text { or } \$ / \text { Therm, etc. } \\
& X_{\text {meas }}=\text { Measured energy use } \\
& X_{97.5}=97.5 \text { percentile of expected energy use } \\
& X_{2.5}=2.5 \text { percentile of expected energy use }
\end{aligned}
$$

\subsection{Prioritization based on broader goals}

As stated above, energy use is a relatively small concern for most organizations. We have demonstrated that broader organizational goals and considerations can be incorporated into the output of the ESTool by adjusting risk tolerance thresholds customizing the cost function. When viewed from another perspective the data contained in the $E_{c}$ vector can reveal more than just the outcome for a five-level signal. Here, we propose a "signal priority ratio" (SR) to summarize the additional information available in the $E_{c}$ vector. Signal priority incorporates all of the foundational components of the ESTool including the other goals embedded in the cost function. The signal priority ratio essentially expresses the ratio of the cost of doing nothing to the cost of taking the recommended action (see Equation 20 below).

$$
S R=\frac{\left(\mathrm{E}_{\mathrm{c}}[3]\right)}{\left(\min \left(E_{c}\right)\right)}=\frac{\text { cost of no action }}{\text { cost of recommended action }}
$$

Consider the following example of calculating the signal priority ratio below, where the minimum term of the expected cost vector is highlighted in bold:

$$
\begin{array}{ccccc}
0 & 2 & 4 & 6 & 8 \\
2 & 0 & 2 & 4 & 6 \\
4 & 2 & 0 & 2 & 4 \\
6 & 4 & 2 & 0 & 2 \\
8 & 6 & 4 & 2 & 0
\end{array} \mid \cdot\left[\begin{array}{l}
0.74 \\
0.07 \\
0.11 \\
0.02 \\
0.06
\end{array}\right]=E_{C_{\mathrm{HVAC}}}=\left[\begin{array}{c}
\mathbf{1 . 1 6} \\
2.14 \\
3.39 \\
5.07 \\
6.84
\end{array}\right] \rightarrow \mathrm{SR}=3.39 / 1.16=\mathbf{2 . 9 2}
$$

Since signal priority ratio is only a scalar quantity, it is only valid to use it for prioritizing actions within each end-use category. 
Corresponding author: Eric Boxer

Email: eric.boxer@colorado.edu

\section{Detailed case study}

The continued development of the Energy Signal Tool theory and application in an open-source detailed energy modeling platform was motivated by a partnership between the National Renewable Energy Lab (NREL) and a large big-box retailer. This case study building, presented in this paper, is a 133,000 sq. $\mathrm{ft}$. big-box retail store, including refrigerated display areas, located in ASHRAE climate zone 6a, which opened in July 2012. NREL and the retailer had worked to design this new prototype store to achieve $50 \%$ energy savings over an ASHRAE 90.1-2004 baseline model. After eight months of operation, NREL completed a follow-up energy study on this prototype building comparing actual consumption to model predictions [38]. It was revealed that the energy savings were not meeting expectations due to excessive natural gas consumption. Through a retro-commissioning exercise on the controls system, it was discovered that HVAC systems had been scheduled to turn on at 3 AM instead of the intended 7 AM. This fault condition is not one that a typical FDD system is set up to detect.

This raised the question of how to discover similar problems at other stores without conducting a detailed energy study of each facility that includes retro-commissioning with a performance benchmark. This becomes especially difficult when a facility is designed to exceed typical performance levels and a peer group cannot be drawn from the building portfolio.

The retailer contracts a third-party service to perform fault detection and diagnostics (FDD) on its monitored systems. They have no intention of an Energy Signal Tool replacing this service due to fast fault response needed for critical systems. The Energy Signal Tool is not capable of responding to faults at this level due to model uncertainty and the computational expense it would require to process and generate reports on an hourly basis. This was further evidence that the greatest value in the Energy Signal Tool would be in prioritizing response to energy related faults, rather than diagnosing the root causes of faults. Once priorities are established by the ESTool, efforts can be focused on using FDD to pinpoint the faults and root causes where it is likely to be most valuable. This helped to shape the notion that the ES Tool is complementary to FDD, not a replacement for it.

\subsection{Case study building energy model}

The building was modeled using the OpenStudio version 1.4.0 graphical user interface to the EnergyPlus simulation engine. A detailed audit performed by NREL during the commissioning process provided much of the information needed to build an accurate model. Some sub-metered energy data gathered over the first year of operation provided further information. Parameter uncertainty analysis, model simplification, and global sensitivity analysis was performed as described in the previous section. Calibration was done to monthly natural gas and electricity utility data. We incorporated actual meteorological year (AMY) weather data spanning the calibration period into the model. All building systems were modeled by auto-sizing so that when several climate zones' TMY weather data were applied to the model, systems could respond appropriately to meet the needs. The auto-sizing function also helped to drastically reduce the number of simulation failures during batch simulation with LHS sampling. 
$<$ Figure 7; 1.5 columns $>$

$<$ Figure 8; 1 Column>

\section{Synthetic fault testing}

To validate the enhancements to the Energy Signal Tool and to test the concepts of fault prioritization, we devised a model-generated fault testing experiment. We use the term "fault" here to indicate that the testing was performed with model scenarios containing faulted conditions. Using these faulted model scenarios, we tested for the ability of the tool to indicate which building models deserve highest action priority. As stated above, we did not expect the ESTool to identify specific root causes of faults. A synthetic testing environment meant that a wide array of faults could be generated at once to test the robustness of the improved ESTool. Synthetic testing also provided a transparent basis to see the interactive effects that a known fault in one end use has on the signals generated for that and others. The questions investigated in this process were, primarily:

1. Which faults are significant enough for the Energy Signal Tool to display an action signal?

2. When an action signal is displayed for a faulted case, how consistently does it correspond to the end-use associated with the root cause of the problem?

3. How closely correlated are the ranks of signal priority ratio and magnitude of the mean expected cost deviation across all faulted cases?

\subsection{Experimental Design}

The following are the details of the experimental process used to test the enhancements of the Energy Signal Tool.

1. Created a calibrated baseline energy model and incorporate probable ranges of uncertainty into a set of uncertain parameters

2. Established end-uses monitored in the model:

a. Whole building energy (WBE)

b. Natural gas energy (NG; heating)

c. HVAC electricity (HVAC; fans, cooling, and heating electricity)

d. Refrigeration electricity (REFR)

3. Applied TMY-3 climate data to the model for three ASHRAE climate zones:

a. Climate zone 3a (warm/humid - Atlanta, Georgia)

b. Climate zone 4c (mild/marine - Portland, Oregon)

c. Climate zone 6a (cold-Milwaukee, Wisconsin)

(All subsequent steps were applied across models for all three climate zones) 
4. Determined significant parameters to each end-use with local and global SA.

5. Calculate risk tolerance thresholds with adjustments for end-use controllability and seasonal normalization.

6. Customized cost functions using the questions presented above for each end-use-being monitored.

7. Computed expected range of performance for nine time periods (an entire year, the months of January, April, July, October, and the last week in each of these months, with 1000 LHS Monte Carlo samples for each time period.

8. Tested the point estimate of the "as-expected" model by treating this output as "observed" consumption. Tuned the base model, the signal tool, and its inputs appropriately so that signals are green for the un-faulted base model.

9. Injected ten typical faults into the base model to create ten separate faulted models. These fault scenarios are described in Table 4 in section 9.2.

10. Placed "measured" data results from these faulted models for all four end-uses in the context of expected consumption to calculated state-space probabilities.

11. Generated signals, expected cost deviations, and signal ratios for each faulted scenario in each of nine time periods, and each of three climate zones.

12. High-level analysis of the results.

a. What was the skill of the signal in detecting correct root causes of faults?

b. Were there secondary effects which made for noisy signal generation?

c. Rank fault signals by each priority metric.

\subsection{Modeling faulted scenarios of the case study building}

Ten faults related to building energy consumption, and especially common to the big-box retail sector were selected with input from the retail partner. To model each fault, we applied first principles and empirical analysis to transform the underlying fault mechanism into altered building control or equipment performance parameters. This is described in similar work of Cheung and Braun [39]. Table 4 lists each fault description, and also shows which end-use categories are known to contain the systems which are at the root cause of each fault. 
Table 4: Fault testing descriptions and modeling assumptions

\begin{tabular}{|c|c|c|}
\hline Fault & Description and model assumptions & $\begin{array}{l}\text { End-use containing } \\
\text { the root cause }\end{array}$ \\
\hline a & $\begin{array}{c}\text { Excess OA; } \\
50 \% \text { OA instead of } 17 \% \text { OA for MAU }\end{array}$ & NGAS, HVAC \\
\hline b & $\begin{array}{l}\text { Economizer no functioning; } \\
\text { No economizer mode for } 1 \text { of } 9 \text { AHUs }\end{array}$ & HVAC \\
\hline c & $\begin{array}{l}\text { Fan belts broken; } \\
\text { Fans scheduled off for } 2 \text { of } 9 \text { AHUs }\end{array}$ & HVAC \\
\hline$d$ & $\begin{array}{l}\text { Refrigeration system degredation; } \\
\text { Refrigeration rack suction piping UA value increased by } 150 \%\end{array}$ & REFR \\
\hline e & $\begin{array}{l}\text { AHU controls scheduling error; } \\
\text { All AHUs turn on at 3am instead of 7am }\end{array}$ & NGAS, HVAC \\
\hline$f$ & $\begin{array}{l}\text { Thermostat night setback/setup not programmed; } \\
\text { No setback / setup at night for heating / cooling thermostat setpoints }\end{array}$ & NGAS, HVAC \\
\hline $\mathrm{g}$ & $\begin{array}{c}\text { Cooling setpoint override by users; } \\
\text { Cooling setpoints are adjusted down } 1.8^{\circ} \mathrm{C}\end{array}$ & HVAC \\
\hline $\mathrm{h}$ & $\begin{array}{l}\text { Heat recovery is being bypassed; } \\
\text { Air-to-air heat exchanger is removed on one large AHU }\end{array}$ & NGAS \\
\hline $\mathrm{i}$ & $\begin{array}{l}\text { Dehumidification control is disabled; } \\
\text { Grocery and sales floor dehumidification system shut off }\end{array}$ & HVAC \\
\hline j & $\begin{array}{l}\text { Thermostat float temperature increase; } \\
\text { Thermostat float increased to } 1.5^{\circ} \mathrm{C} \text { for all zones }\end{array}$ & NGAS, HVAC \\
\hline
\end{tabular}

\subsection{Testing across several climate zones}

A portfolio of multiple buildings can extend across several climate zones and testing the ESTool across several climate zones can be an informative process. Having several climate zones presents a situation where the cost function should be customized. For example, a heating system in climate zone $3 \mathrm{~A}$ has a higher ratio of (cost to maintain) / (cost to operate) than it would in colder climate 6A. There is also a different expression of seasonal variation in each climate zone; heating and cooling systems' consumption is more variable in climates $6 \mathrm{~A}$ and $3 \mathrm{~A}$ than in climate zone $4 \mathrm{C}$. Finally, synthetic fault testing of the ESTool is made more interesting by having three climate zones because the same fault has different severity in each climate zone.

\section{Results of synthetic fault testing}

We modeled each of the ten fault scenarios (descriptions given in Table 4 in section 9.2) across three climate zones over a year, and split results into nine time periods of mixed duration (one week, one month, and one year). For synthetic testing purposes, each of these results segments is considered to be 
"observed data". We then placed the "observed data" in the context of the probable range of energy consumption generated by Monte Carlo sampling of model based energy consumption and followed the methods outlined above to obtain an action signal for each of the four end-uses.

\subsection{Examples of individual building fault assessment}

Below are two detailed example results, showing the signals generated for faults $a$ and $j$. Each example is presented as a set of signals corresponding to the end-use PDFs above it. Given at the top of each PFD in Figure 9 are the calculated values of the $M_{1 a}$ and $M_{2 a}$ risk tolerance probability masses. To the right of each of the PDFs, the calculated values of state probability masses are shown, along with the measured consumption (" $X_{\text {meas }}$ ") from the faulted model. Shown below each of the signal graphics in Figure 10 is the signal priority ratio, as well as the $95 \%$ confidence interval of cost deviation.

<Figure 9, 2 columns>

<Figure 10, 2 columns>

Figure 9 above shows the measured consumption of the "faulted" building with an excessive thermostat deadband range in the context of the probable consumption distribution for the month of October. As evidenced by the graph of whole building energy in the upper left-hand corner of the figure, the thermostat deadband error had little impact on the scale of whole-building energy use. However, by sub-metering HVAC energy, it was possible to see a significant deviation from the median of the probable HVAC energy consumption and therefore send an action signal. The high yellow light for the refrigeration electricity end-use in Figure 10 reflects the added refrigeration energy needed to compensate for higher indoor temperature fluctuation. However, it is considered a false signal because it does not prescribe action to address the end-use category in which the problem originates.

<Figure 11, 2 columns>

<Figure 12, 2 columns>

Figure 11 above shows the measured consumption of the "faulted" building with excess outdoor air in the context of the probable consumption PDF for the month of July. Note the skewness of the distribution for natural gas consumption; this is due to the tendency for uncertainties to lead to higher natural gas use rather than could propagate to lower usage during this month. With additional outside air in this hottest month, HVAC electricity usage is observed slightly higher than the expected median. The high level of outside air was not significant enough to generate immediate action signals in Figure 12 , only signals indicating an issue that needs to be monitored. This is due to summer cooling loads being dominated by solar and internal gains. It is easily imagined how this fault is much more significant in the winter when heating loads are heavily dependent on outside airflow rates.

\subsection{Portfolio level analysis}

The ten distinct faults across three climate zones collectively make up 30 unique building fault scenarios. This amount of data is sufficient to explore the portfolio maintenance prioritization support that the 
ESTool provides. Rather than displaying 30 sets of traffic lights, the quantitative output of the ESTool can be used in a more compact manner appropriate for prioritizing actions in response to faulty operation at the portfolio level. As discussed, above, the two quantitative outputs of the Energy Signal Tool are signal priority ratio and probable range of energy cost deviation. We reiterate that the signal priority ratio is just a scalar, not a quantity whose magnitude has any direct meaning other than ranking actions for one end-use across multiple buildings. In the presentation of results below, all cost deviations have been converted to absolute value for ease of comparison.

The following figures show the results of the top 15 faults for each end-use for all three climate zones in a year-long retrospective monitoring period. For brevity, only results for natural gas and HVAC end-uses are presented. The results are ranked in descending order of priority according to signal priority ratio (shown at right in each figure), with comparison of deviation from mean expected cost shown at left. On the graphs, both scales are shown logarithmically to provide a better view of the entire range of signal priority and cost deviation values. Signal priority ratios, can be compared among buildings for the same end-use. Not surprisingly, the outdoor air damper fault (Fault $a$ ) produced a cost deviation in climate 6a that ranked higher than any other fault for the first three end-uses. Fan malfunction (Fault $c$ ) exhibited the greatest variability in terms of action urgency across the three climate zones. This can be explained by the fact that in the mild climate $4 \mathrm{c}$, the main function of the fan is to provide ventilation air to the building - rather than heating or cooling. Meanwhile, the fans serve in large part to provide heating to climate $6 a$ (highest priority in natural gas end-use of the three), and provide cooling to climate $3 a$. In a portfolio analysis application, the labels for climate zone and fault would be replaced by building identifiers. When integrated into a web-based dashboard, this system of visualization could facilitate prioritizing energy management efforts.

<Figure 13, 1.5 columns>

$<$ Figure 14, 1.5 columns>

It is often the case that retrofit strategies are deployed across an entire building portfolio that spans a broad geographic area without consideration of which locations would benefit the most, or what uncertainties there may be in the outcomes. The same analysis methods shown above for prioritizing maintenance could be applied to a portfolio of buildings under consideration for retrofit. Instead of modeling faults, the user would model retrofit opportunities. Then, the output of the ESTool essentially informs the portfolio manager of which buildings will benefit most because of (or be poor candidates for) the retrofit.

\subsection{Signal classification skill metric}

The purpose of the Energy Signal Tool is to detect faulty operational states and prioritize them to help focus FDD efforts that will diagnose specific faults. To this end, an effective Energy Signal Tool will consistently identify faults when they are present (have a high frequency of detection), and have a low rate of sending false alarms. Yuill and Braun [40] note that the false alarm is an especially critical metric 
of fault detection (presented here as decision support) because taking action on the wrong root cause of a fault can be costly.

Rather than assessing the skill of the tool based on the signal type or magnitude, classification skill shall be based on whether or not a signal corresponds to a fault. Each signal can be classified in one of the following four categories, based on the knowledge of which synthetic model fault it is in response to:

TP: True positive; a signal for action is given and it corresponds to the root cause end-use fault

FP: False positive; a signal for action is given which does not correspond to the root cause, or when no fault is present

TN: True negative; no action is prescribed, and the end-use is not faulted

FN: False negative; no action is prescribed, when actually the end-use is faulted

From the enumeration of these classification categories, two useful metrics arise:

1. Recall; what percentage of faults are identified?

2. False Alarm Ratio (FAR); what percentage of signals call for unneeded action?

Where equations 1 and 2 give the formulae for Recall and FAR

$$
\begin{aligned}
\text { Recall } & =\frac{T P}{T P+F N} \\
F A R & =\frac{F P}{F P+T N}
\end{aligned}
$$

In terms of fault detection capability, the rate of Recall is significant for its measure of sensitivity to faults. False negative signals are cases of missed action. A false negative signal may be produced when the risk tolerance boundaries are wide enough to absorb the energy consumption deviation generated by a fault. A false negative in whole building energy may be produced when two end-uses see opposite changes in energy consumption and cancel out. The FAR metric estimates the percentage of spurious actions prescribed by the tool. In facilities management, this can be compared to the percentage of maintenance calls that result in actions having little impact or addressing the wrong root cause.

\subsection{Discussion of skill testing results}

In this work, skill metrics were applied to all four sub-metered end-uses to assess 1,080 signal outputs. The following figures summarize these results:

$<$ Figure 15, 2 columns>

$<$ Figure 16, 2 columns> 
Figure 16 shows the Energy Signal Tool achieves a high rate of recall for schedule-related faults, including HVAC scheduling error (fault $e$ ), and thermostat setback / setup error (fault $f$ ), in the model representing the cold climate zone. There was a lower rate of recall for these same schedule-related faults (faults $e$ and $f$ ) in the mild climate 4c. This can be attributed to the reduced need for environmental conditioning during the nighttime hours of this climate. As expected, the tool was also more sensitive to detecting dehumidification system malfunction (fault $i$ ) in the warm moist climate zones. The heat exchanger bypass condition (fault $h$ ) was detected most often in the mild climate 4a, since the heat recovery device, when operating well in this climate, will often eliminate what would have been a need for mechanical cooling.. The signal tool was not sufficiently sensitive to detect fault $b$, a faulty economizer in one of nine air-handling units. This fault did not have a significant impact on energy consumption relative to the expected uncertainty and risk tolerance threshold for deviation in any end-use.

The most common causes of false alarms were the interactive effects among end-uses in the synthetic fault model runs. For example, a cooling setpoint override (fault $g$ ) led to action signals for excessive natural gas consumption due to simultaneous heating and cooling. When indoor humidity controls were modeled to fail (fault $i$ ), there was a significant increase in refrigeration energy that led to false alarms in all climate zones. This is to be expected in buildings; a fault rooted in one end-use category will often propagate to consumption shifts in another. Some false alarms among end-uses may be more valuable than whole-building energy data where an increase in consumption of one end-use is masked by a decrease in another.

In practice, taking skill metrics will help the facilities manager tune the sensitivity of the tool to the desired degree. Yuill and Braun [40] used what was termed a Fault Impact Ratio to establish the performance threshold of capacity or efficiency degradation in unitary air conditioning equipment where fault detection would be desired. The risk tolerance thresholds built into the basis of the Energy Signal Tool are what set the level of energy use deviation in each end-use that triggers an action signal.

\section{Conclusions and future work}

Through work with an industry partner, as well as additional literature review, we refined the concept for an Energy Signal Tool as originally introduced by Henze et al. [5]. First, risk tolerance thresholds are now based on end-use consumption distributions. This was crucial to address cases where an arbitrary percentage of consumption deviation could have exceeded the range of likely energy distribution for an end-use. Second, we now adjust risk tolerance thresholds according to the level of accountability the building operator has for each end-use. Third, the concept of allowing additional risk tolerance during seasons of low consumption was developed, which is important to prevent excessive false alarms being generated. Fourth, we have demonstrated two ways of enriching the output of the Energy Signal Tool with priority level. This is crucial for a decision support tool that is intended to inform costly decisions, and is better suited to prioritize fault responses than identify root causes.

Integrating a larger set of uncertain parameters into the pre-screening process provides an opportunity for future work. Empirical evidence of parameter uncertainty characterizations could be gathered. 
Including significant uncertainties in parameters such as controls scheduling, hours of use and hours of occupancy will require more advanced programming abilities of detailed energy simulation software. With additional programming advancements, it may be possible to attain a higher level of model calibration that can enhance the ESTool, including schedule definition, by calibrating to measured hourly data rather than monthly data.

Rather than being best suited for single building fault detection, we have made a case for broadening the application of the ESTool to portfolio energy management. Testing results indicated that the ESTool is only moderately skilled at identifying the root causes of faults with multiple building systems interactions. In contrast, quickly assessing whole-building and end-use performance to prioritize which buildings have the most potential for both energy savings and achieving broader organizational goals is the ESTool's greatest strength. The results of signal prioritization and skill metrics show that the tool is able to discern differences in severity of a single fault in similar buildings located in distinct climate zones. This application could also extend to retrofit prioritization given minimal adjustments to the process taken here.

The skill metrics taken on the assessment of results from the faulted model scenarios show room for improvement in the balance of false alarms and rate of recall. Fault $e$ existed in the case study building before retro-commissioning. The ESTool had a $100 \%$ rate of recall for this fault in the original climate zone. However, much higher than expected natural gas use produced a high rate of false alarms in climate 6 a. The portfolio manager would have been able to identify the fault, but would have a hard time deciding whether to focus further efforts to identify the root cause in the HVAC system in general or specifically on the natural gas heating equipment. In the future, Bayesian inference could be used to examine signal patterns across several end-use categories and compare them to the root causes discovered after detailed investigation.

Future work to link the Energy Signal Tool with building management system (BMS) generated data and FDD would be useful. Typical BMS systems have come to include features that incorporate system measurements such as loop temperatures and rates of energy consumption. These inputs would be valuable to updating model calibration and could make for improved granularity in end-use monitoring. This could result in a seamless way to identify which buildings have severe faults, and then look to a FDD system or human expert to diagnose the root cause of those high-priority faults. This could generate a concise report for the building operator including prioritization based on energy cost as well as other organizational goals. 


\section{ACKNOWLEDGEMENTS}

The authors would like to acknowledge the support of the National Renewable Energy Laboratory (NREL) for partial funding of this work. The authors extend special thanks to Ron Judkoff for his engaging in deep discussions regarding this project throughout its development. Thanks also to many other scientists in the NREL Commercial Buildings group for their bountiful technical advice. 


\section{REFERENCES}

[1] C. Turner, M. Frankel. "Energy performance of LEED for new construction buildings." New Buildings Institute 4 (2008) 1-42.

[2] P. De Wilde. "The gap between predicted and measured energy performance of buildings: A framework for investigation." Automation in Construction 41 (2014) 40-49.

[3] NSTC. "Submetering of Building Energy and Water Usage: Analysis and Recommendations of the Subcommittee on buildings technology research and development". National Science and Technology Council Committee on Technology (NSTC), Washington DC. Report; October, 2011.

[4] J. Granderson, M.A. Piette, G. Ghatikar. "Building energy information systems: user case studies." Energy Efficiency 4.1 (2011) 17-30.

[5] G.P. Henze, G.S. Pavlak, A.R. Florita, R.H. Dodier, A.I. Hirsch. "An energy signal tool for decision support in building energy systems." Applied Energy 138 (2015) 51-70.

[6] Energy Star Portfolio Manager. Web, 03/15/15 <https://www.energystar.gov/buildings/aboutus/how-can-we-help-you/benchmark-energy-use>

[7] Commercial Buildings Energy Consumption Survey. Web, 02/28/15 <https://www.eia.gov/consumption/commercial/>

[8] X. Gao, A. Malkawi. "A new methodology for building energy performance benchmarking: An approach based on intelligent clustering algorithm." Energy and Buildings 84 (2014): 607-616.

[9] A. Hinge, J. Rutherford, D. Abrey, J. DaSilva, E. Titus, E. Smyth. "Back to school on energy benchmarking." Proceedings of the 2002 ACEEE Summer Study on Energy Efficiency in Buildings. Monterey, CA. (2002).

[10] R. Hedrick, V. Smith, K. Field. "Restaurant Energy Use Benchmarking Guideline." Contract 303 (2011) 275-3000.

[11] BuildingIQ. Web, 06/23/16 <https://buildingiq.com>

[12] Ecova Facility Optimization. Web, 06/23/16 <https://www.ecova.com/solution/facilityoptimization/>

[13] A. Saltelli, K. Chan, E.M. Scott. (Eds.). Sensitivity analysis. Vol. 1. New York: Wiley, 2000.

[14] S. de Wit. "Uncertainty in Building Simulation". <In: Malkawi, A. M., Augenbroe, G., editors, Advanced Building Simulation, 2003. pp. 25-59>

[15] C.J. Hopfe, J.L. Hensen. "Uncertainty analysis in building performance simulation for design support." Energy and Buildings 43.10 (2011) 2798-2805.

[16] A.T. Booth, R. Choudhary. "Decision making under uncertainty in the retrofit analysis of the UK housing stock: Implications for the Green Deal." Energy and Buildings 64 (2013) 292-308.

[17] L. Wang, P. Mathew, X. Pang. "Uncertainties in energy consumption introduced by building operations and weather for a medium-size office building." Energy and Buildings 53 (2012) 152 158.

[18] S. Bucking, R. Zmeureanu, A. Athienitis. "A methodology for identifying the influence of design variations on building energy performance." Journal of Building Performance Simulation 7.6 (2014) 411-426.

[19] C. Struck, J.L. Hensen. "On supporting design decisions in conceptual design addressing specification uncertainties using performance simulation." Proceedings of the 10th IBPSA Building Simulation Conference, Beijing, China, 2007. pp. 1434-1439.

[20] P. Heiselberg, H. Brohus, A. Hesselholt, H. Rasmussen, E. Seinre, S. Thomas. "Application of sensitivity analysis in design of sustainable buildings." Renewable Energy 34.9 (2009) 2030-2036.

[21] S. de Wit, G. Augenbroe. "Analysis of uncertainty in building design evaluations and its implications." Energy and Buildings 34.9 (2002) 951-958.

[22] A. Saltelli, M. Ratto, T. Andres, F. Campolongo, J. Cariboni, D. Gatelli, et al. Global Sensitivity Analysis: The Primer. J Wiley and Sons, 2008.

[23] Y. Heo, R. Choudhary, G.A. Augenbroe. "Calibration of building energy models for retrofit analysis under uncertainty." Energy and Buildings 47 (2012) 550-560.

[24] M.C. Kennedy, A. O'Hagan. "Bayesian calibration of computer models." Journal of the Royal Statistical Society: Series B (Statistical Methodology) 63.3 (2001) 425-464.

[25] T.A. Reddy. Applied data analysis and modeling for energy engineers and scientists. Springer, 2011. 
[26] S. Burhenne. "Monte Carlo Based Uncertainty and Sensitivity Analysis for Building Performance Simulation". PhD Thesis. Fraunhofer Institute for Solar Energy Systems, Germany. November, 2013.

[27] L.C. Harmer, G.P. Henze. "Using calibrated energy models for building commissioning and load prediction." Energy and Buildings 92 (2015) 204-215.

[28] N.L. Long, B.L. Ball, K.A. Fleming, D. L. Macumber. Scaling Building Energy Modeling Horizontally in the Cloud with OpenStudio. No. NREL/CP-5500-62199. NREL (National Renewable Energy Laboratory (NREL), 2014.

[29] D.L. Macumber, B.L. Ball, N.L. Long, "A graphical tool for cloud-based building energy simulation," in 2014 ASHRAE/IBPSA-USA Building Simulation Conference, 2014, pp. 87-94.

[30] I.A. Macdonald. Quantifying the effects of uncertainty in building simulation. University of Strathclyde, 2002.

[31] V. Corrado, H.E. Mechri. "Uncertainty and sensitivity analysis for building energy rating." Journal of Building Physics (2009) 125:156.

[32] F. Domínguez-Muñoz., B. Anderson, J.M. Cejudo-López, A. Carrillo-Andrés. "Uncertainty in the thermal conductivity of insulation materials." Proceedings of the eleventh IBPSA Conference. Glasgow, Scotland; July 27-30, 2009. doi:10.1016/j.enbuild.2010.07.006

[33] J. Stein, F. Kung. Retail Building Guide for Entrance Energy Efficiency Measures. No. NREL/BK5500-52290. National Renewable Energy Laboratory (NREL), Golden, CO., 2012.

[34] B. Eisenhower, Z. O'Neill, V.A. Fonoberov, I. Mezić. "Uncertainty and sensitivity decomposition of building energy models." Journal of Building Performance Simulation 5.3 (2012) 171-184.

[35] Handbook, A.S.H.R.A.E. "Fundamentals 2013." Atlanta, USA: ASHRAE (2013).

[36] D.C. Montgomery, G.C Runger. Applied Statistics and Probability for Engineers, 6th edition. Wiley, 2013.

[37] Guideline, A.S.H.R.A.E. "Guideline 14-2002, Measurement of Energy and Demand Savings." American Society of Heating, Ventilating, and Air Conditioning Engineers, Atlanta, Georgia, (2002).

[38] A. Hirsch, M. Deru, R. Langner, G. Stark, I. Doebber, J. Scheib, et al. Results and Lessons Learned From the DOE Commercial Building Partnerships. National Renewable Energy Laboratory (NREL), Golden, CO., 2014.

[39] H. Cheung, J.E. Braun. Development of Fault Models for Hybrid Fault Detection and Diagnostics Algorithm. October 1, 2014--May 5, 2015. No. NREL/SR-5500-65030. National Renewable Energy Laboratory (NREL), Golden, CO., 2015.

[40] D.P. Yuill, J.E. Braun. "Evaluating the performance of fault detection and diagnostics protocols applied to air-cooled unitary air-conditioning equipment." HVAC\&R Research 19.7 (2013) 882891. 
Figures need to be rendered in color for the online electrocnic journal.

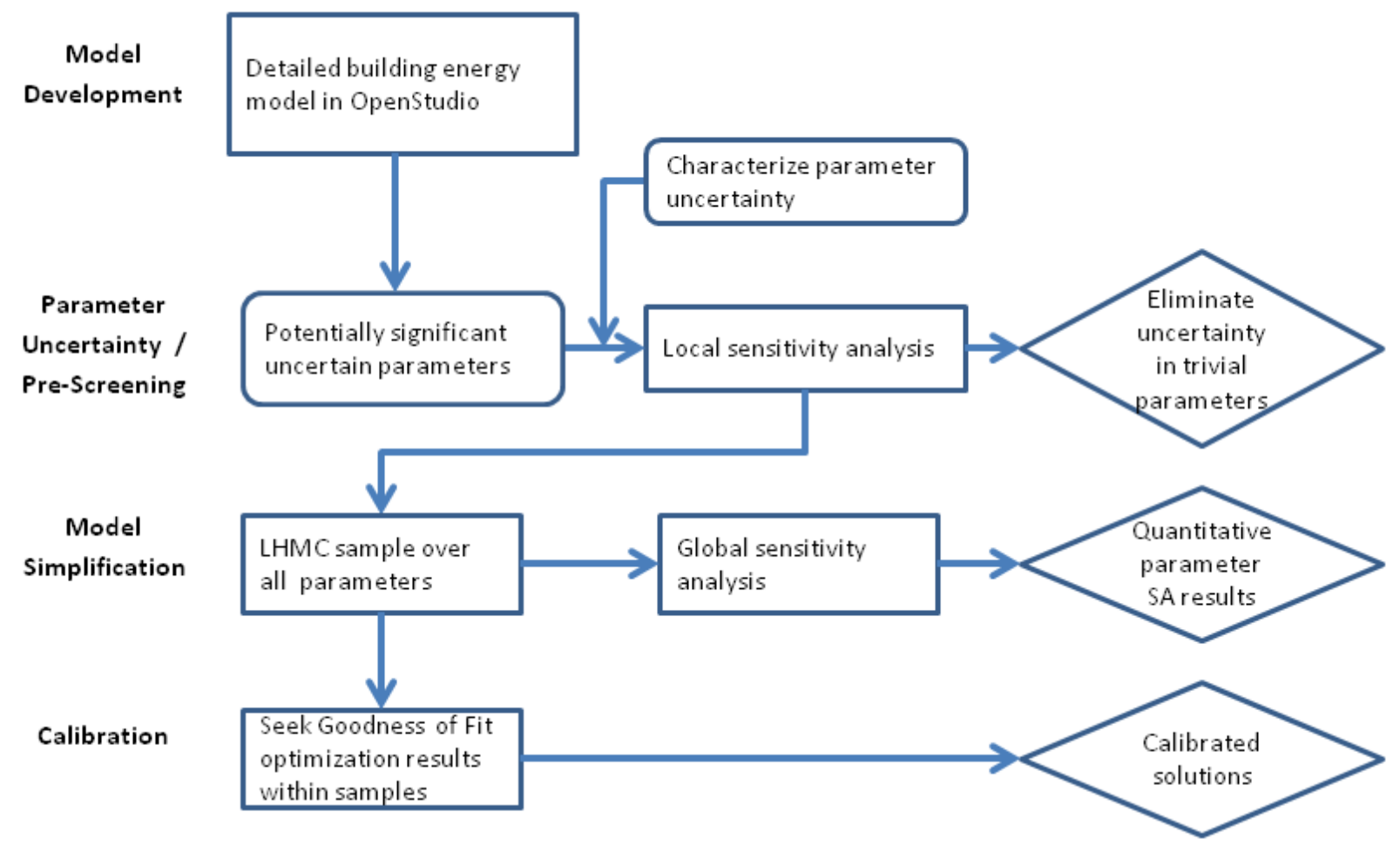

Figure 1: 1.5-columns

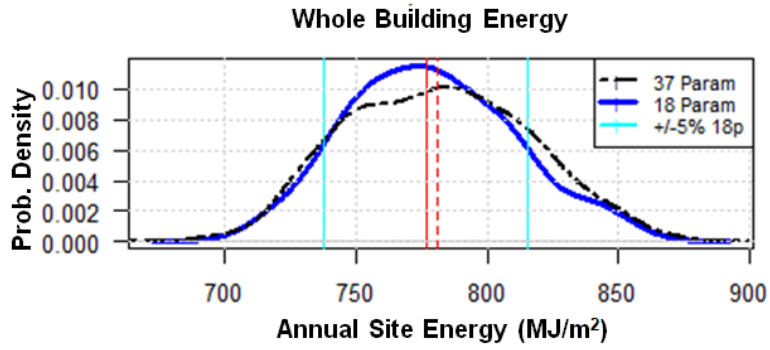

HVAC Electricity

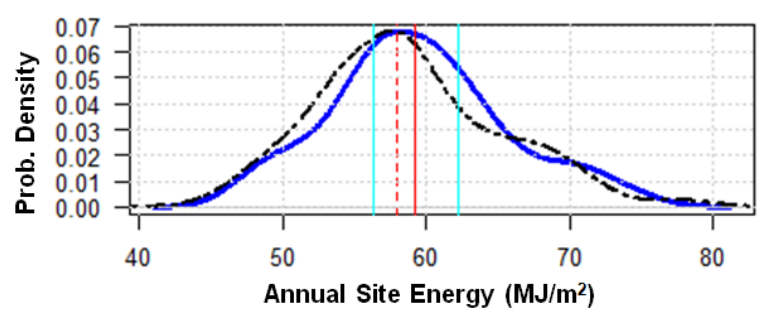

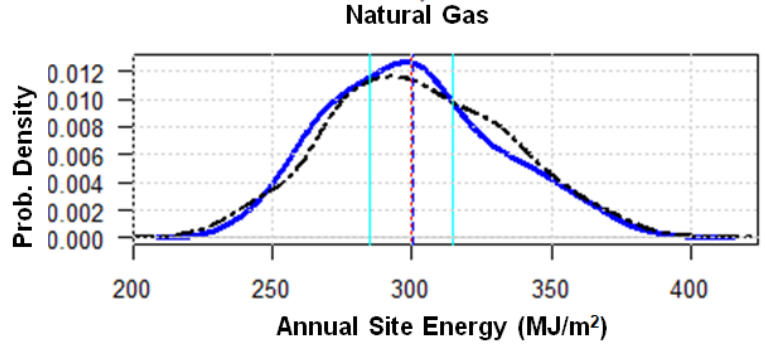

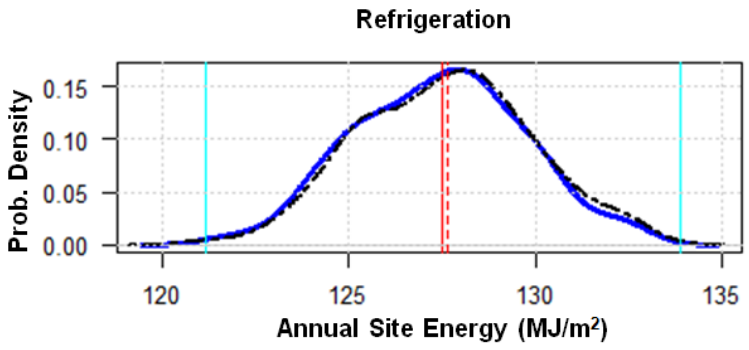

Figure 2: 1.5-columns 


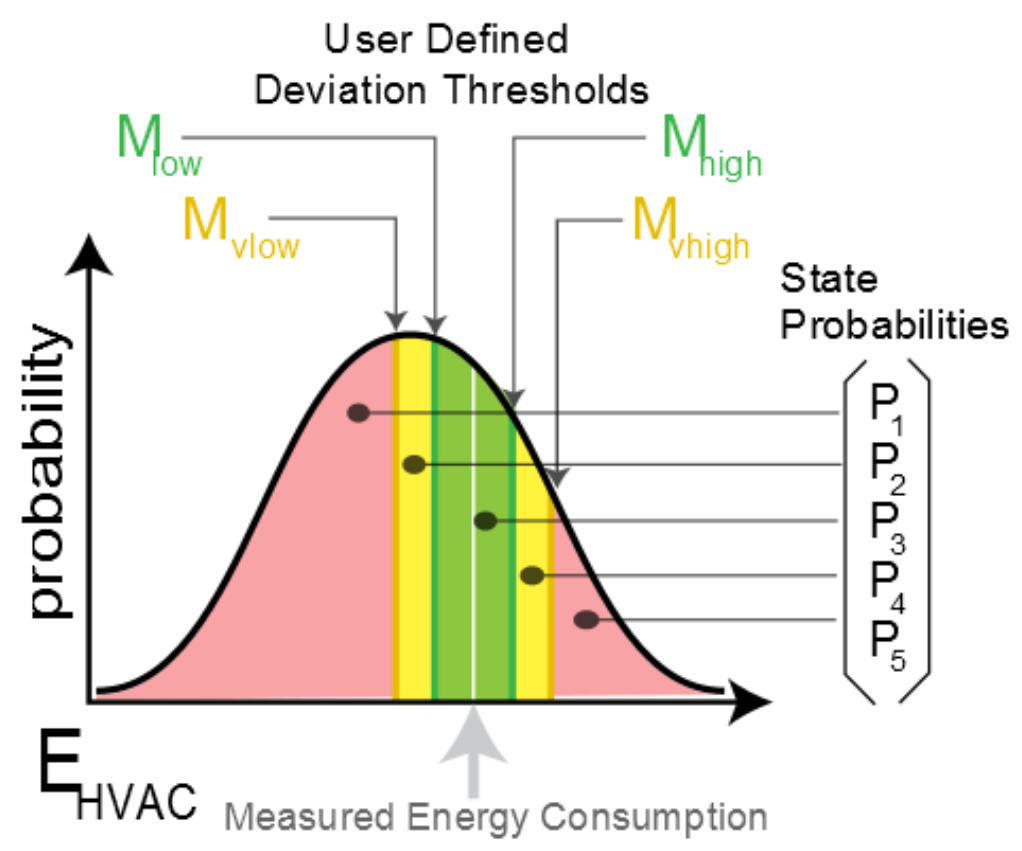

Figure 3: 1-column
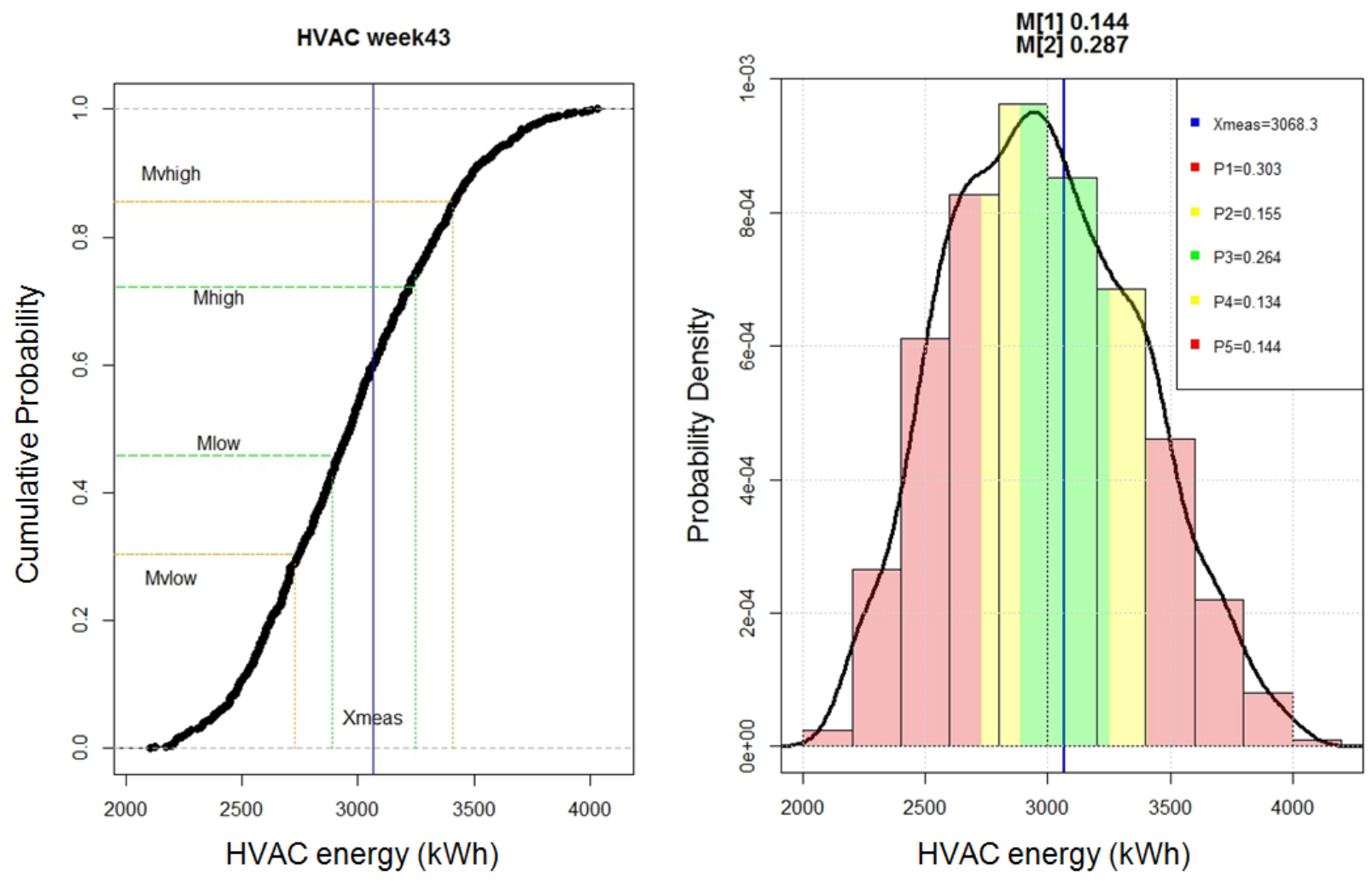

Figure 4: 2-columns 


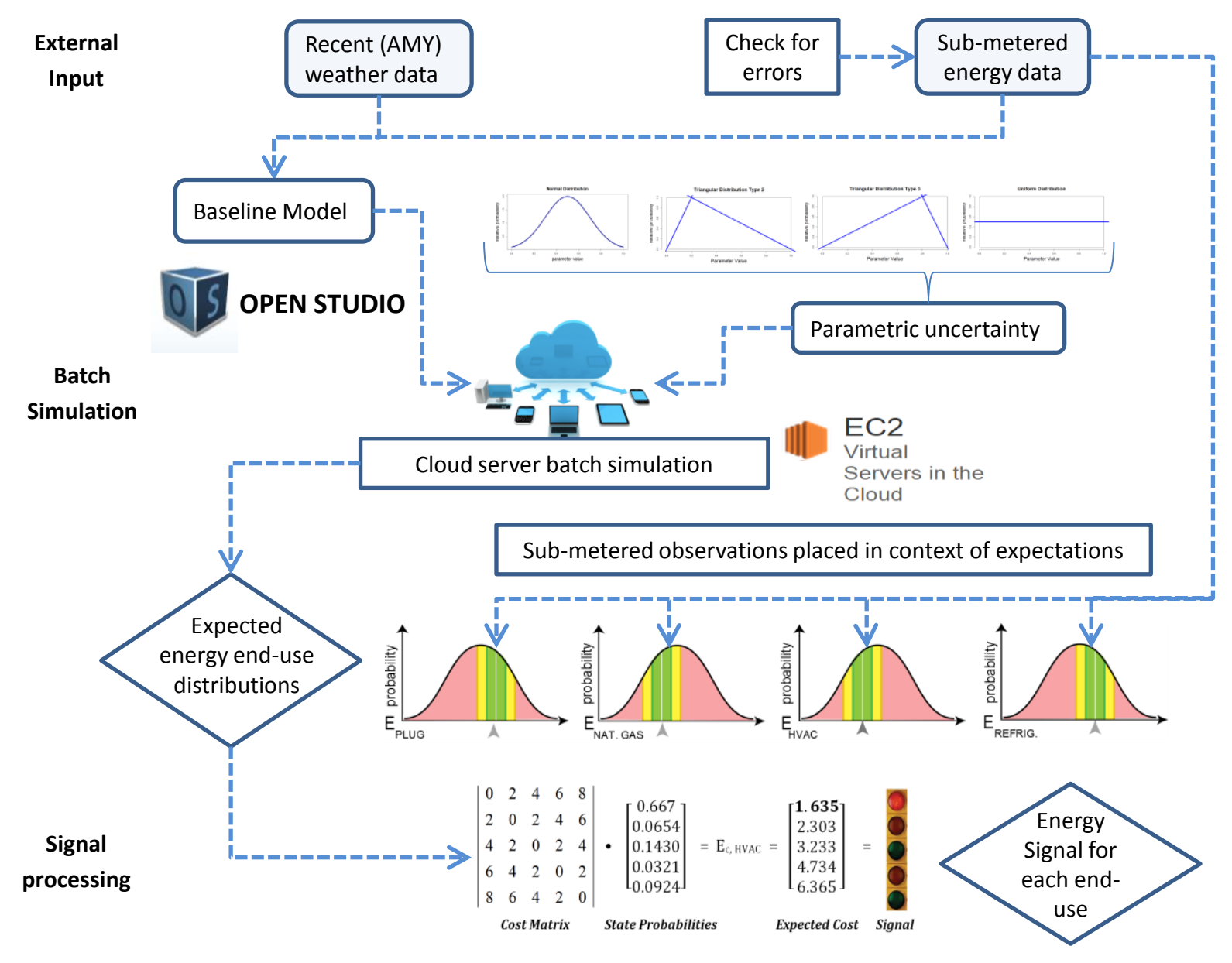

Figure 5: 2-columns

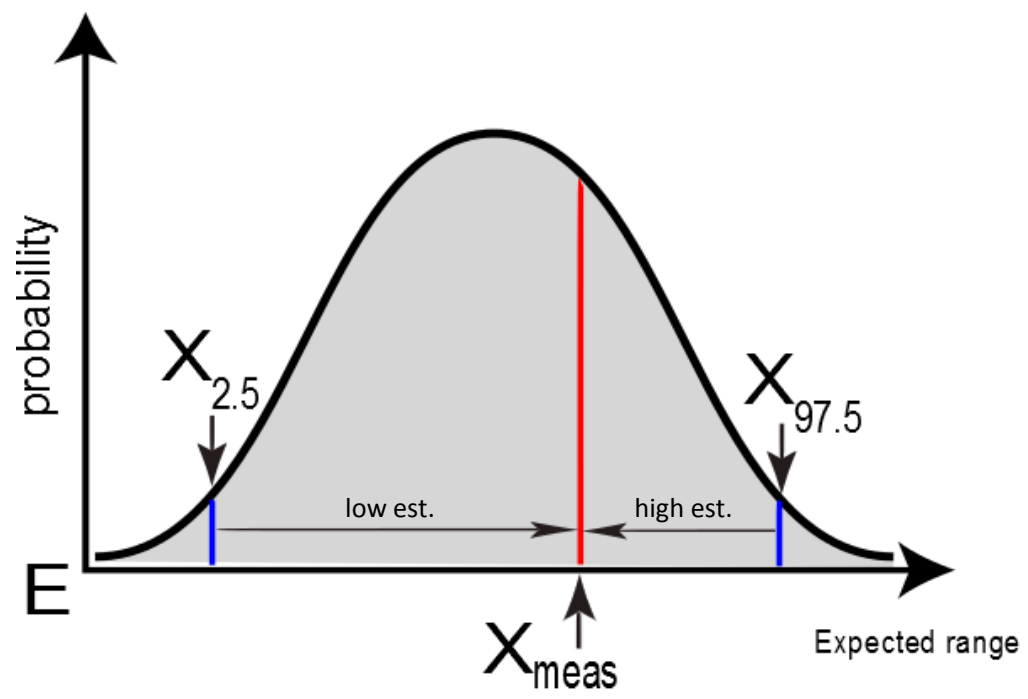

Figure 6: 1-column 


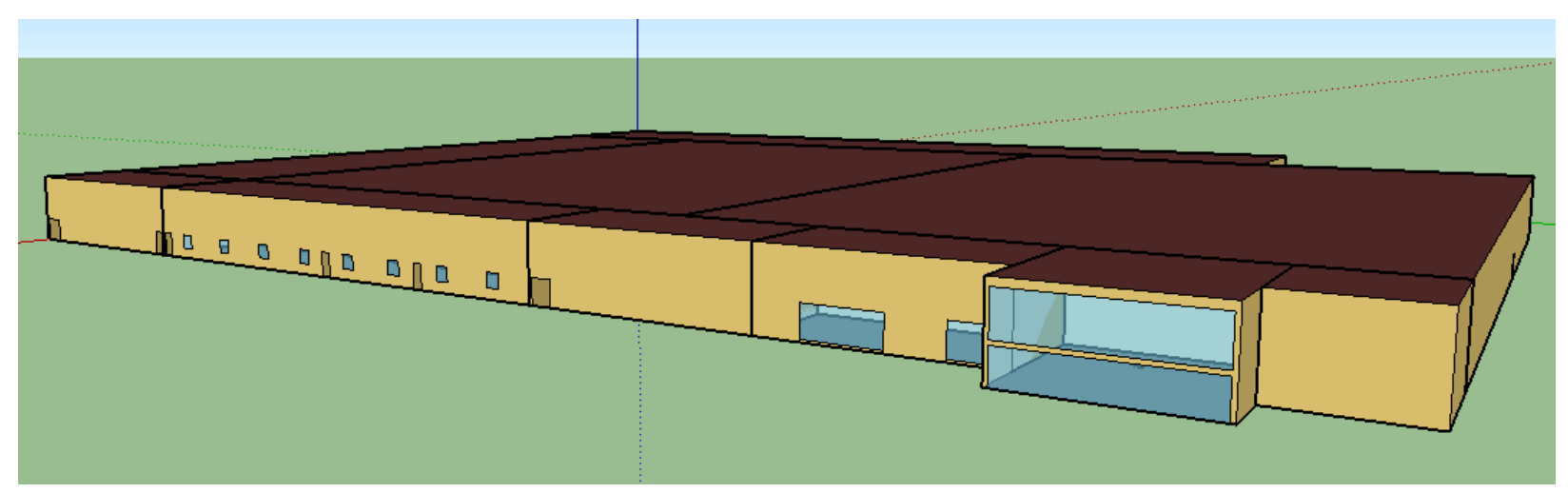

Figure 7: 1.5-columns

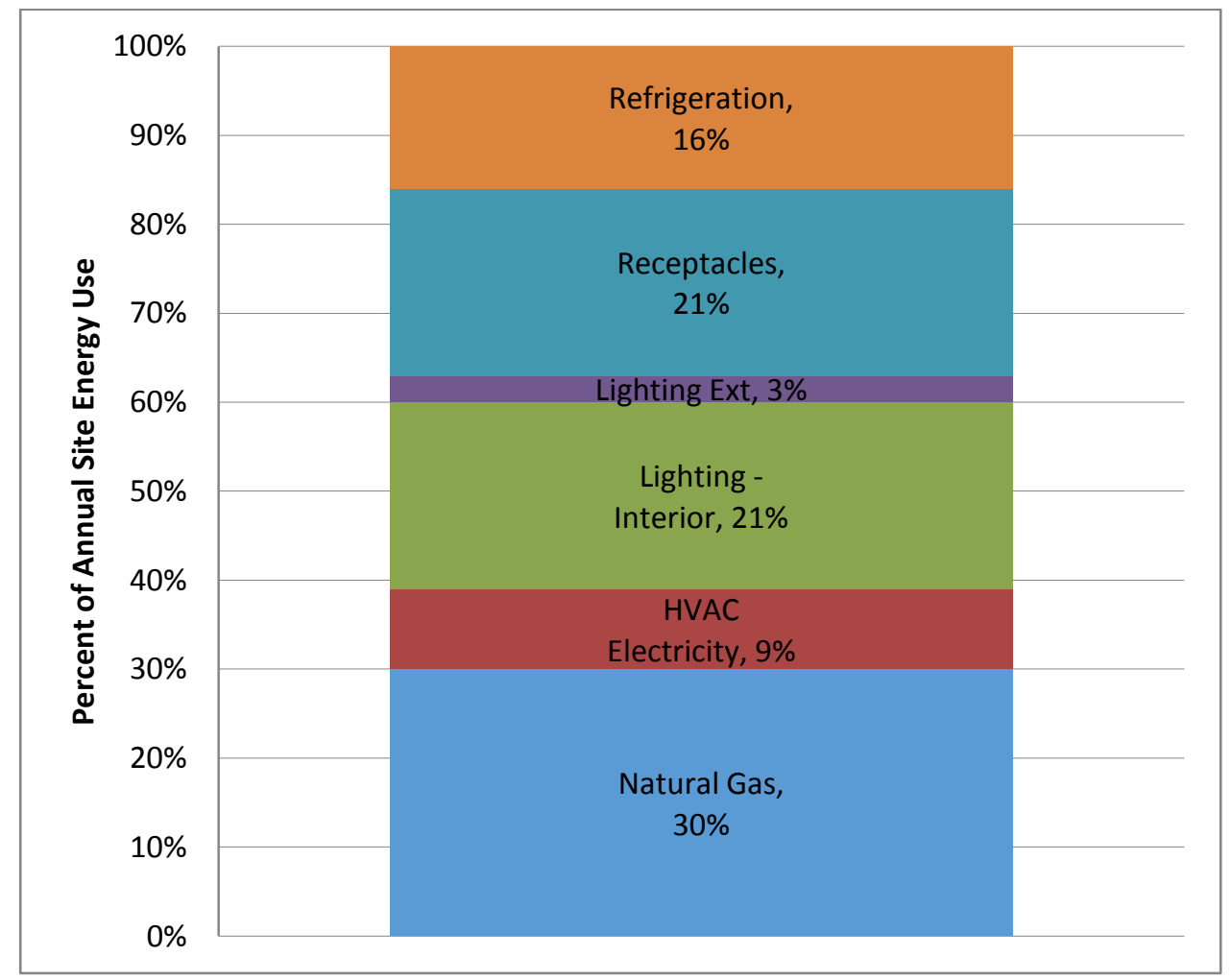

Figure 8: 1-column 

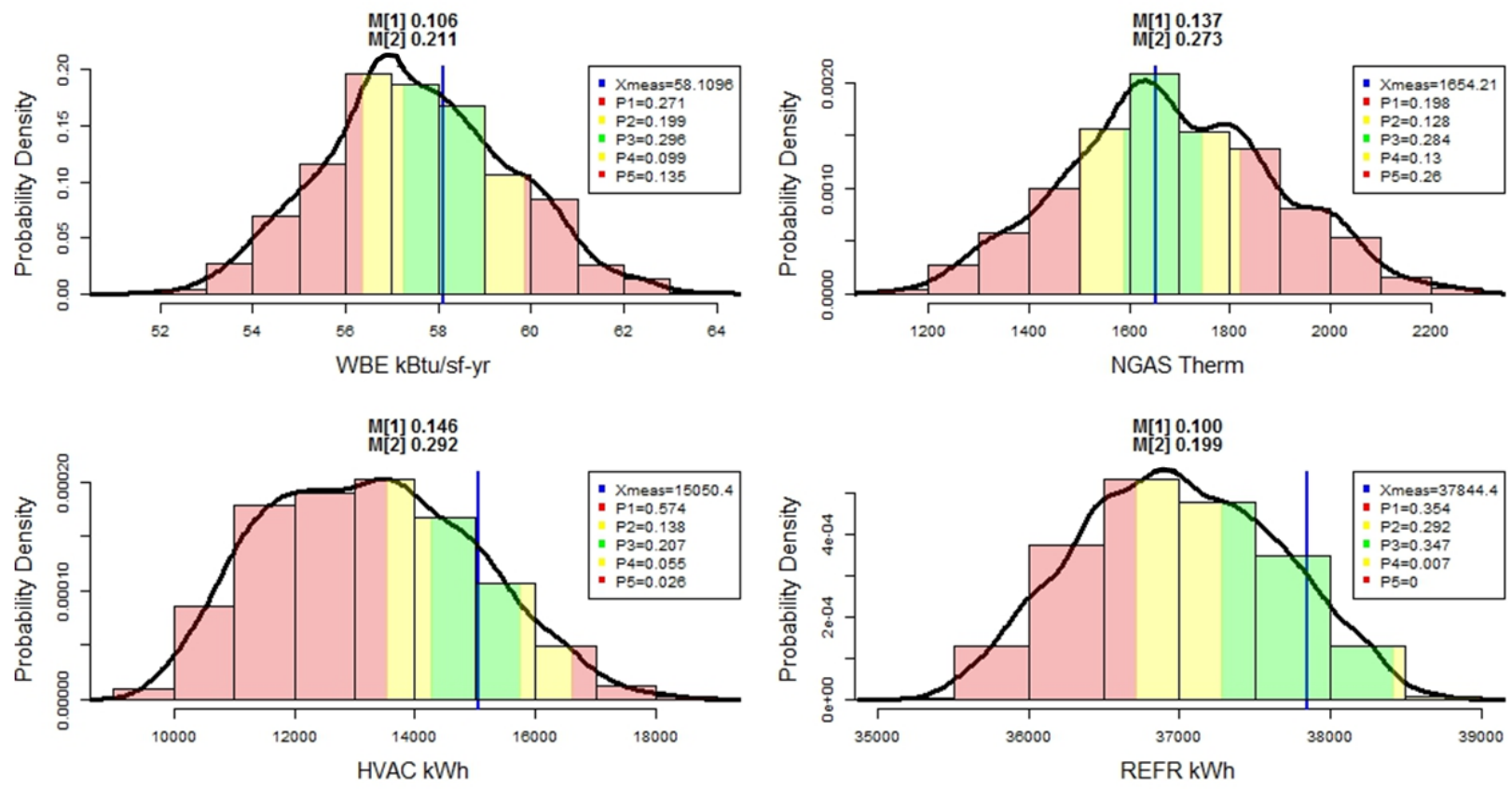

Figure 9: 2-columns

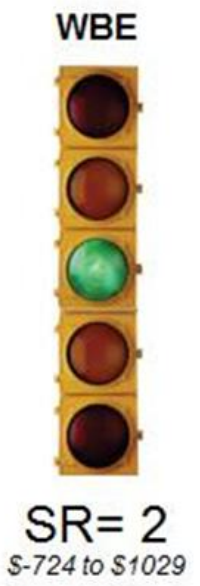

NGAS

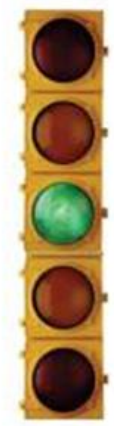

$\mathrm{SR}=1.7$
HVAC

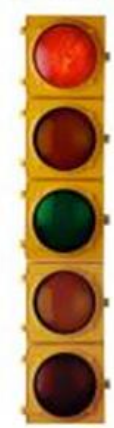

$\mathrm{SR}=3.4$

S-119 to $\$ 443$
REFR

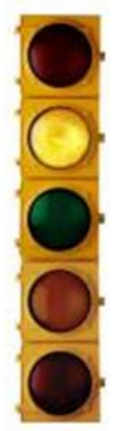

$\mathrm{SR}=4.4$

Figure 10: 2-columns 

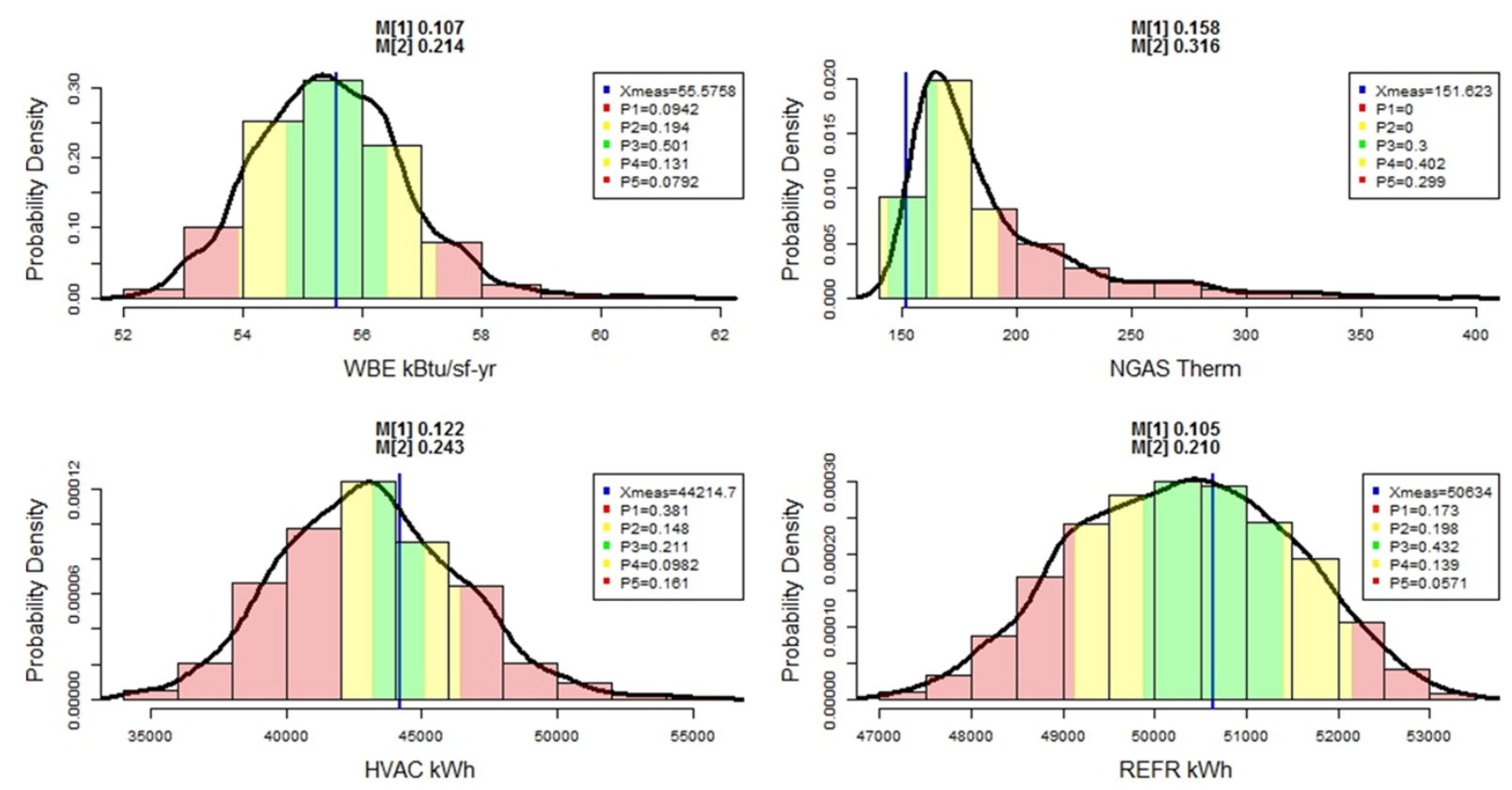

Figure 11: 2-columns.


S-160 to $\$ 230$

Figure 12: 2-columns 


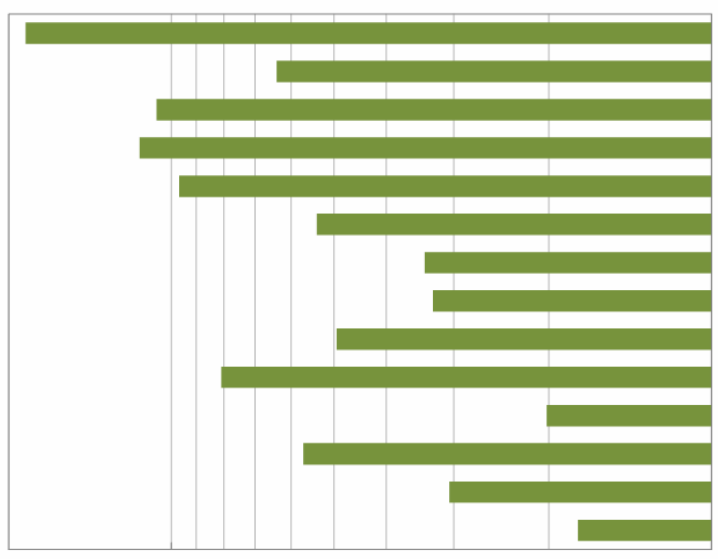

$\$ 10,000$

log (Mean Probable Cost Deviation)

Figure 13: 1.5-columns

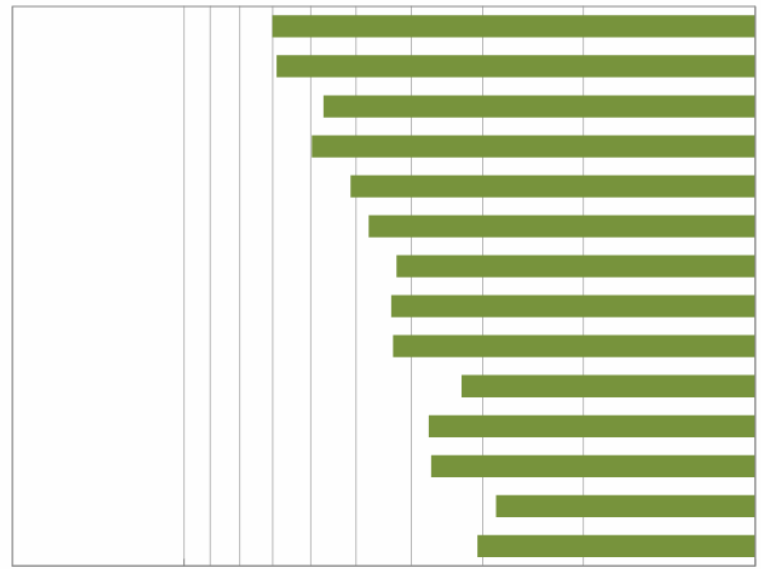

$\$ 10,000$

$\log$ (Mean Probable Cost Deviation)

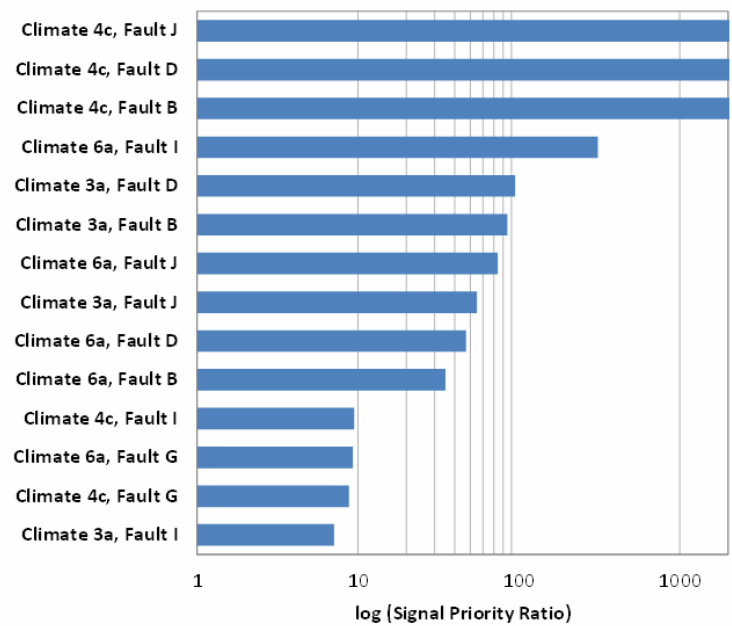

$\log$ (Signal Priority Ratio)

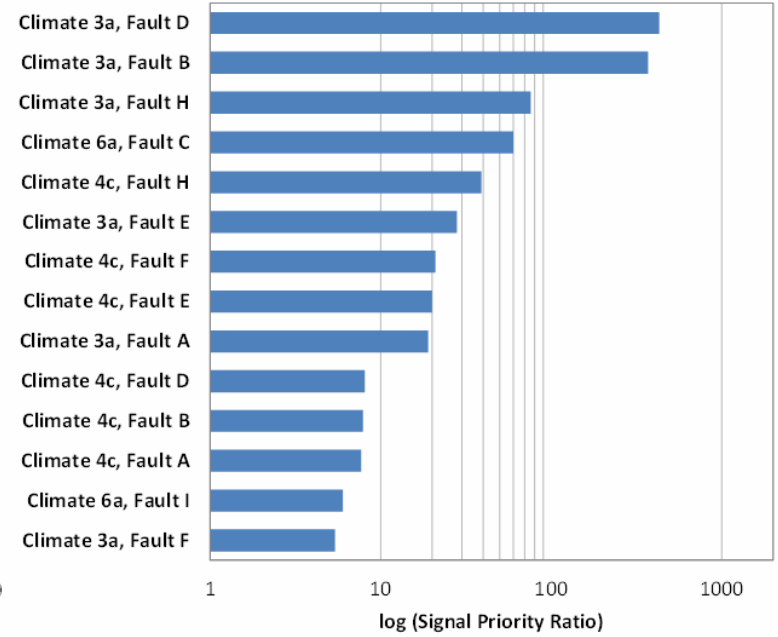

Climate 3a, Fault D

Climate 3a, Fault

ate $4 c$, Fault $F$

Climate 4c, Fault E

Climate 4c, Fault B

Climate 4c, Fault A

Climate 6a, Fault

Climate 3a, Fault F

log (Signal Priority Ratio)

Figure 14: 1.5-columns

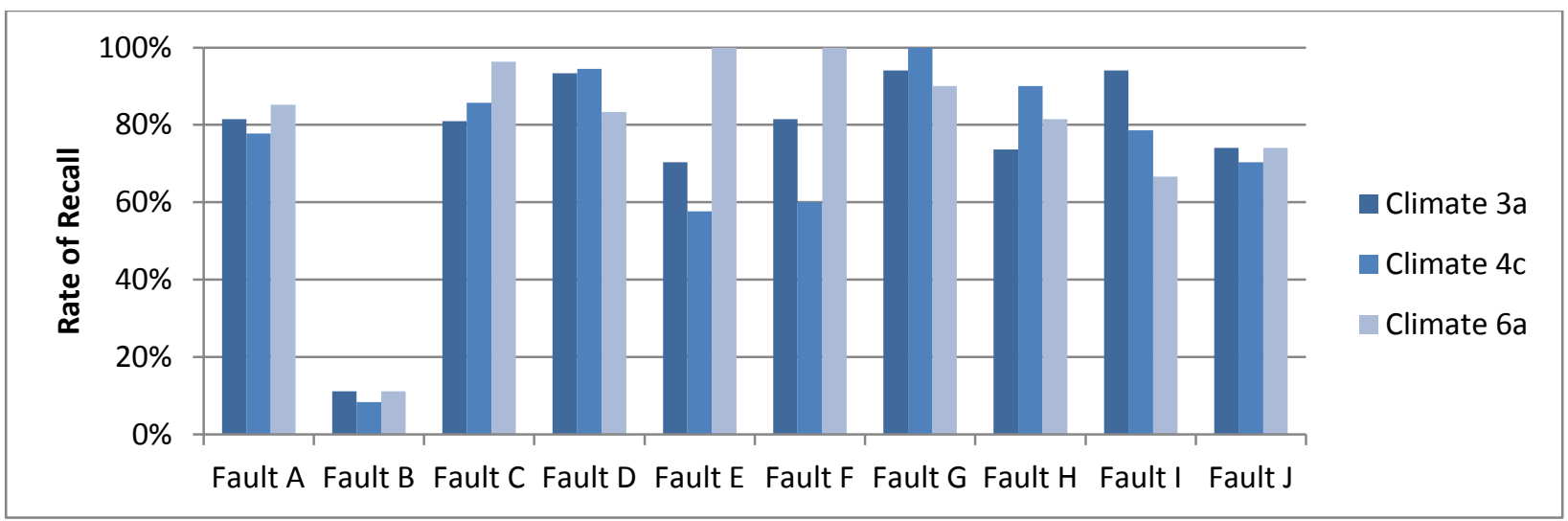

Figure 15: 2-columns 


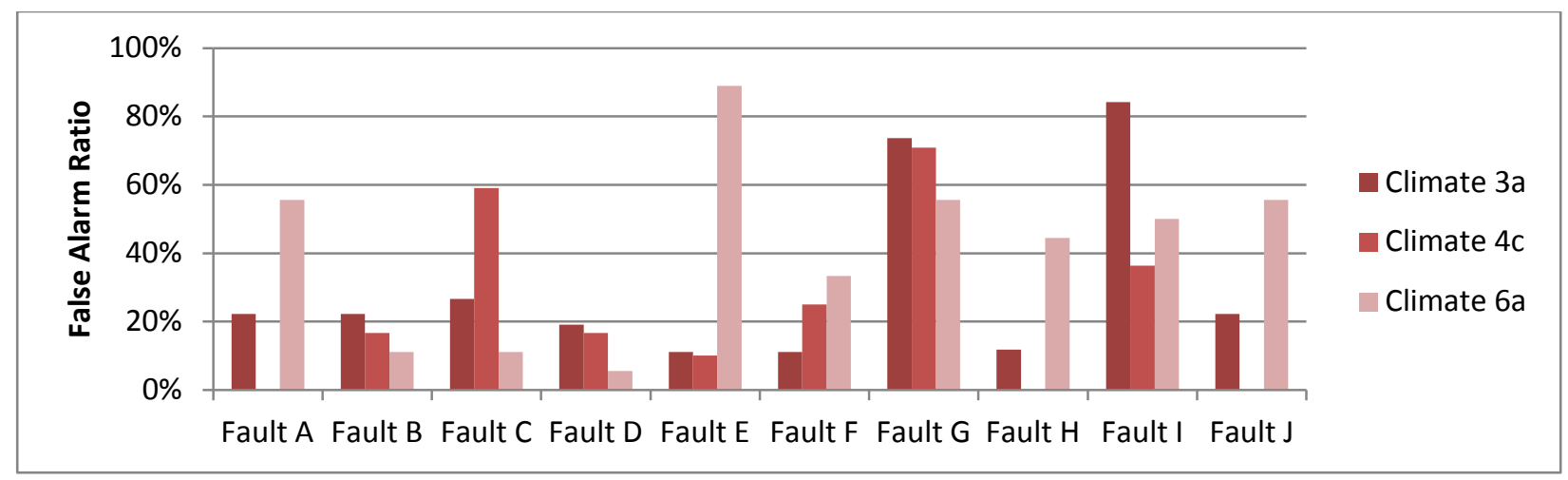

Figure 16: 2-columns

>> Figure Captions $<<<$

Figure 1: Model development workflow

Figure 2: PDF comparison of original and simplified model outcome across all end-uses

Figure 3: Basic probability distribution of expected energy end-use consumption (adapted from Henze et al. [5])

Figure 4: Sample output of CDF and PDF with expected consumption, measured data, and risk tolerance thresholds

Figure 5: Workflow for generating expected end-use distributions and energy signal

Figure 6: Deriving the probable range of energy cost deviation

Figure 7: Isometric rendering of modeled case study retail building

Figure 8: Annual energy by end-use as measured at the case study building

Figure 9: PDFs for fault $j$, in October, in climate zone 6 a.

Figure 10: Signals, priority ratios, and cost deviation for fault $j$, in October, in climate zone 6 .

Figure 11: PDFs for fault $a$, in July, in climate zone 3a.

Figure 12: Signals for fault $a$, in July, in climate zone 3a.

Figure 13: Top 15 faults in yearly natural gas energy end-use, in descending signal priority ratio

Figure 14: Top 15 faults in yearly HVAC energy end-use, in descending signal priority ratio

Figure 15: Summary of recall metrics for ten faults in three climate zones

Figure 16: Summary of false alarm ratio (FAR) metrics for ten faults in three climate zones 